AperTO - Archivio Istituzionale Open Access dell'Università di Torino

\title{
Sample preparation for trace analysis by chromatographic methods
}

\section{This is the author's manuscript}

Original Citation:

\section{Availability:}

This version is available http://hdl.handle.net/2318/79872

since

Published version:

DOI:10.1080/10826076.2010.484371

Terms of use:

Open Access

Anyone can freely access the full text of works made available as "Open Access". Works made available under a Creative Commons license can be used according to the terms and conditions of said license. Use of all other works requires consent of the right holder (author or publisher) if not exempted from copyright protection by the applicable law. 


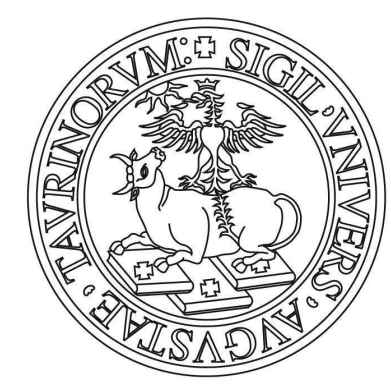

\section{UNIVERSITÀ DEGLI STUDI DI TORINO}

\section{This is an author version of the contribution published on: \\ Questa è la versione dell'autore dell'opera:}

R. I. Olariu, D. Vione, N. Grinberg, C. Arsene. Sample Preparation for Trace Analysis by Chromatographic Methods. J. Liq. Chromatogr. Relat. Technol. 2010, 33, 1174-1207.

DOI: $10.1080 / 10826076.2010 .484371$.

The definitive version is available at:

La versione definitiva è disponibile alla URL:

http://www.tandfonline.com 


\title{
Sample preparation for trace analysis by chromatographic methods
}

\author{
Romeo-Iulian Olariu ${ }^{1}$, Davide Vione ${ }^{2}$, Nelu Grinberg ${ }^{3}$ and Cecilia Arsene ${ }^{1, *}$ \\ ${ }^{1}$ Department of Chemistry, Faculty of Chemistry, Laboratory of Analytical Chemistry, “Al. I. Cuza” University \\ of Iasi, Carol I 11, 700506 Iasi, Romania \\ ${ }^{2}$ Dipartimento di Chimica Analitica, Università di Torino, Via Pietro Giuria 5, 10125 Torino, Italy \\ ${ }^{3}$ Boehringer Ingelheim Pharmaceuticals Inc., 900 Ridgebury Rd., Ridgefield, CT 06877-0368 \\ "corresponding author: carsene@uaic.ro
}

\begin{abstract}
The determination of trace analytes in complex natural matrices often requires extensive sample extraction and preparation prior to chromatographic analysis. Correct sample preparation can reduce analysis time, sources of error, enhance sensitivity and enable unequivocal identification, confirmation and quantification. This overview considers general aspects on sample preparation techniques for trace analysis in various matrices. The discussed extraction/enrichment techniques cover classical methods, such as Soxhlet and liquid-liquid extractions along with more recently developed techniques like pressurized liquid extraction, liquid phase microextraction (LPME), accelerated microwave extraction, and ultrasoundassisted extraction. This overview also deals with more selective methodologies, such as solid phase extraction (SPE), solid phase microextraction (SPME) and stir bar sorptive extraction (SBSE). The adopted approach considers the equilibriums involved in each technique. The applicability of each technique in environmental, food, biological and pharmaceutical analyses is discussed, particularly for the determination of trace organic compounds by chromatographic methods.
\end{abstract}

Keywords: chromatographic analysis, sample preparation, enrichment techniques, liquidliquid, liquid-solid, gas-liquid, gas-solid equilibriums.

\section{Introduction}

It has long been established that knowledge on complex chemical systems in matrices of interest for the human beings, in various ways, is critically dependent on chromatographic methods. Sensitive and robust analytical methods, among which chromatography is quoted by far as the most important, have been widely used during the past decades to investigate and 
identify various chemical compounds characterized by varying degrees of structural complexity.

Modern analysis involves undertaking each single step of a complete analytical diagram flow, beginning with the definition and outline of the problem and ending with a detailed critical evaluation of the relevant analytical data which allows the presentation of the analytical result. Sample preparation and the use of adequate analytical methods represent the bridge between the two aforementioned steps, which will be largely dependent upon analyst experience.

In practical work, analysis of trace chemicals entails more than the mere qualitative or quantitative detection and identification of a particular element or chemical compound. It involves knowledge of the origin and structure of the sample matrix, and also the analyst's insight into analogous problems from other disciplines to assure the plausibility of the questions raised and to critically evaluate and interpret the results. It is suggested that these preliminary observations are essential in trace analysis, where an important focus is in sample preparation. Nevertheless, it is admitted that tools, equipment, and methodological principles are common to both general chemical analysis and modern trace analysis. ${ }^{[1]}$

The concentration levels of target analytes found in environmental, biological, food and drugs samples are generally too low to allow a direct injection into a chromatographic system. Changing solvent, temperature, pressure, phases or volumes are among the main tools used by analysts in order to solve a complex chromatographic problem. Most of the sample preparation techniques rely on analytical steps including trapping of the analytes of interest on various media, desorption and analysis (mainly by chromatography). Poor sensitivity, the major problem in these procedures, is presently overcome by including on-line combination of extraction with liquid chromatography and injection of large volumes into the analytical system, i.e. gas chromatography. ${ }^{[2]}$

The main goal of sample pretreatment is to make complex samples suitable for chromatographic analysis. ${ }^{[3]}$ This prerequisite is necessary to reach detectable concentration of the target analyte and to isolate the analytes from very complex matrices.

Quite often, the sample preparation in chromatographic methods is representing a tedious, time-consuming, and error-prone step of an analytical procedure. Therefore, it is generally regarded as the rate-limiting step in chemical analysis. It has been suggested that a large part of the time typically required to perform analytical tasks is spent on sample preparation. ${ }^{[4]}$ Indeed, sample pretreatment is frequently performed by off-line methods, e.g. liquid-liquid extraction and solid-phase extraction. These procedures are usually performed manually, they are laborious and time-consuming and sometimes lack of precision and accuracy. 


\section{The state-of-the-art in chromatographic investigations toward sample preparation. A general approach}

At the beginning of the chromatographic technique, insufficient detection limits and the occurrence of many problems with sample preparation and separation, preventing the analysis of real samples, were often acknowledged as major challenging aspects that chemists were facing in their experimental work. ${ }^{[5]}$ Recent progress in instrumental analytical chemistry has resulted in the availability of methods that allow monitoring of various chemicals at parts per trillion (ppt) and even parts per quadrillion (ppq) range.

An important number of papers and of fundamental and comprehensive reviews brought attention into the scientific community to the importance of choosing and using suitable analytical techniques for the determination of trace residues and contaminants in complex matrices. Presently, a topic arising great concern and interest is the analysis of the potential genotoxic impurities (PGIs) in pharmaceutical products. PGIs have received increased consideration over the last years. ${ }^{[6]}$ A threshold of toxicological concern (TTC) value of 1.5 $\mu \mathrm{g}$ day $^{-1}$ has been developed as an acceptable risk associated with the intake of a genotoxic impurity. ${ }^{[7]}$ Analyzing the PGIs, even at low ppm levels in active pharmaceutical ingredients (APIs), is a challenging task which presently can be performed through the use of state-of-theart technology. Quantifying chemicals at such low levels seems to be currently not feasible in order to routinely control the level of the impurities which might reside in active pharmaceutical products and, beside the demand for sensitivity to detect trace concentrations, matrix interference and selectivity will represent important issues to overcome. ${ }^{[6]}$ Modern hyphenated techniques, involving static headspace sampling (SHS) coupled with capillary gas chromatography interfaced to mass spectrometry (GC-MS) are presently available for the analysis of halides and haloalkenes, ${ }^{[8]}$ while in situ derivatization by SHS-GC-MS is more suitable for the analysis of aryl- and alkyl sulfonates. ${ }^{[9]}$ Vanhoenacker et al. in 2009 propose a sample preparation method where liquid chromatography (LC) is preferred for the analysis of less volatile solutes. ${ }^{[6]}$

Presently, a number of reviews and original papers is available over the state-of-the-art of chromatographic methods for residue analysis of pharmaceuticals in samples of environmental concern, ${ }^{[10]}$ for trace residues and contaminants in foods and drinks, ${ }^{[11-13]}$ for mycotoxins in biological tissues ${ }^{[14]}$ or for surfactants (e.g. alkylbenzene sulfonates, ethoxylated nonionic surfactants, metabolites) in river water or wastewater. ${ }^{[15,16]}$ Major modern sample preparation techniques for the extraction and analysis of medicinal plants were reviewed by Hue in 2002, and the author concludes that the solid-phase microextraction represents the most suitable alternative for the sampling of volatile compounds before chromatographic analysis. ${ }^{[17]}$ Baltussen et al., in an excellent review regarding sorptive sample preparation, conclude that this is a valuable strategy to overcome the limitations of the 
adsorptive sampling. The technique is used in combination with thermal desorption for the analysis of very apolar analytes, i.e. alkanes, alkenes and aromatics. ${ }^{[2]}$

As far as sample preparation is concerned, the hyphenation of various techniques has been gaining importance over the past decades. Sample pre-concentration and clean-up methods hyphenated with core analytical techniques are acknowledged as powerful tools to accomplish the task of low-level detection. ${ }^{[18]}$ Hyphenated (coupled or hybrid) techniques, coupling chromatographic separation with sensitive and specific detectors (usually mass spectrometry), has recently become one of the most powerful instrumental tools in speciation analysis and the characterization of complex samples.

Liquid or gas chromatographic methods coupled with mass spectrometric detection play an increasingly important role in environmental analysis, especially in the aquatic environment and in water treatment. ${ }^{[19,20]}$ Hydrophilic interaction chromatography (HILIC) hyphenated with mass-spectrometry (MS) is a potentially powerful technique in the quantitative analysis of drugs and drug metabolites. ${ }^{[21]}$ High-performance liquid chromatography stability-indicating methods are particularly attractive for the determination of active substances (e.g., ascorbic acid) and for the quantification of potentially occurring degradates in pharmaceutical/cosmetic preparations, developed as oil-in-water emulsion and aqueous gel. ${ }^{[22]}$ Such a method presents convenience, rapidity and the ability to separate substances quantitatively without pre-derivatization.

There is also an important number of reports which refer to fast, simple, sensitive and efficient sample preparation methods prior to analytical detection of a wide range of persistent organochlorine pollutants, ${ }^{[23]}$ polychlorinated biphenyls in soils, ${ }^{[24]}$ iodixanol used as contrasting agent, ${ }^{[25]}$ sodium azide used as a preservative, ${ }^{[26]}$ pharmaceuticals, drugs, anesthetics and metabolites, ${ }^{[27-36]}$ and even adjuvants (epichlorohydrin) in paper and pharmaceutical industries. ${ }^{[37]}$ Presently, also in the enantioselective analysis of various drugs marketed as racemic mixtures, tedious sample preparation methods turned towards more rapid and feasible procedures. ${ }^{[38]}$

It is generally agreed that the works that are mainly serum/plasma related are especially important for assessment studies of health issues related to human exposure. ${ }^{[23]}$ However, matrices of physiological concern, i.e. plasma, serum and biological tissues, were previously assigned as being particularly complex, with numerous sample preparation problems. ${ }^{[27]}$ Major problems that should be addressed in the sample preparation step are the presence of interference masking the analytes of interest, of non-analytes progressively reducing the performance of the analytical column, and the variability between the samples induced by the multitude of the non-analytes.

Presently, limits of the chromatographic methods to simultaneously detect several watersoluble vitamins in complex matrices require identification and use of separate assay methods. Sample preparation, sensitivity of the detection method that is used, and equipment costs are 
among the main problems limiting the use of chromatographic methods in routine analysis of e.g. ascorbic acid. Therefore, it is suggested that chromatographic methods be replaced by flow injection analysis (FIA) based on spectrophotometric or electroanalytical detectors, which is a more suitable tool to solve analytical problems characterized by time-consuming procedures of extraction, reaction and analysis, or when only one analyte has to be determined in a large number of samples. ${ }^{[39]}$ However in 2003, Iwase et al. supplied excellent preparative aspects for the routine chromatographic analysis of ascorbic acid in food. ${ }^{[40]}$ Vinci et al. in 1995 claim that, by improving the chromatographic conditions and the sample pretreatment operations, it is possible to optimize and make easier the overall procedure of analysis of ascorbic acid in fruits with high nutritional value, which contain generally high levels of hydrosoluble vitamins. ${ }^{[41]}$

In samples of environmental concern, the methods used to isolate trace volatiles for gas chromatographic analysis may have profound effects on the resultant chromatograms. ${ }^{[42]} \mathrm{Per}$ se injection was the usual method used in the past for the analysis of samples containing lowboiling petroleum fractions or essential oils. Additional problems may occur with samples containing large amounts of water, alcohol or nonvolatile materials (including most food products), or samples containing volatile compounds as dilute vapor systems (e.g., air or headspace gases).

In some cases, the development of appropriate preparation steps is also a crucial prerequisite for studies intended at understanding the separation process at the molecular level, where both experimental observation and theory must be put forth. ${ }^{[43-47]}$

High sensitivity with no column overloading and adequate resolution are challenging tasks which can be solved nowadays. On-line on-column derivatization at controlled temperature is regarded as a useful method for the analysis of an active aldehyde, ${ }^{[48]}$ while online column-switching devices combined with advanced separation media technologies is regarded as a suitable technique for the analysis of complex matrices, e.g. mixtures of enantiomers specific for various cardiovascular drugs. ${ }^{[49]}$ Presently, ultra high pressure liquid chromatography is largely used for fast enantiomeric separation of chiral molecules, ${ }^{[50,51]}$ the absolute configuration of the enantiomeric analytes being assessed with the help of the vibrational circular dichroism (VCD). VCD is a technique capable of solving problems of absolute stereochemistry ${ }^{[52]}$ under specific experimental conditions. ${ }^{[53]}$

Lowering the temperature at which the separation occurs is a suitable alternative to studying active compounds or unstable molecules. Extensive in-column cyclization of an analyte, occurring at room temperature, can be significantly diminished when working at subambient temperature. ${ }^{[54]}$ 


\section{The choice of a suitable sorbent phase}

Various materials are successfully used for the selective adsorption of the analytes of interest from complex matrices, although undesired effects (incomplete desorption, artifact formation) may also occur. $^{[2]}$ The sorbent materials can be adopted as stationary phases in chromatography, or employed in the step of sample preparation for extraction and clean-up purposes. Many research groups have attempted to prepare suitable sorbents for the separation of various compounds. Production of novel capillary GC stationary phases based on persubstituted cyclodextrins have attracted a great deal of attention during the past decades, especially for their potential application in the separation of chiral silicon compounds. ${ }^{[55]}$

Fundamental studies on intermolecular interactions influencing solute retention on novel carbon surfaces prepared by vapor deposition on porous zirconia microspheres proves that these carbon sorbents may considerably improve the chromatographic separation. ${ }^{[56]}$

The introduction of polar embedded-phases, containing polar moieties within an alkyl chain, involves changing the chemistry of the stationary phase itself in order to set-up parameters to improve the selectivity or reproducibility. Modeling studies have proved that reduced peak tailing can be obtained with the use of stationary phases with embedded polar groups, compared with conventional alkylsilane phases. ${ }^{[57]}$

Strong cation-exchange supports are suitable extractors for the determination of Triton-X 100 , a surfactant used in reaction mixtures in order to increase the solubility of various compounds and to provide homogeneous reaction environments. For instance, it is used as a surfactant in the presence of quinoline derivatives from the leukotriene $\mathrm{D}_{4}$ class, which is a therapeutic agent with a potentially important role in the etiology of various diseases. Development of flow injection methods with on-line solid-phase extraction offered the most suitable solutions to solve practical aspects related to the instrumental maintenance, which also enabled the chromatographic columns to operate for longer times. The method is solving also a complex problem regarding the analysis of a surfactant which appears as a mixture of various oligomers, with important implications in its quantification. Flow injection analysis with on-line solid phase extraction represent a simple, rapid and accurate method for Triton-X 100 determination. ${ }^{[58,59]}$

On a C18 hybrid stationary phase, using pure water as a mobile phase at temperature above $100{ }^{\circ} \mathrm{C}$, a temperature range where the solvation properties of pressurized hot water change, it is possible to separate complex mixture of organic constituents in a short time

period. ${ }^{[60,61]}$ Under such conditions it is possible to separate at least twelve anilines in less than ten minutes, ${ }^{[61]}$ to be compared with a total analysis time of about 80 minutes as reported by Gennaro et al. ${ }^{[62]}$ 


\section{Methods of analyte isolation and concentration/Enrichment techniques}

The choice of the suitable extraction/enrichment techniques for the recovery of trace chemicals from various samples (biological, drugs, environmental, food and drinks) must take into account the sensitivity, selectivity and separation capabilities of the selected analytical method, the complexity of the sample, and last but not least the chemical and physical characteristics of the analytes. ${ }^{[15]}$

In the last few years, on-line dialysis has been successfully applied to the LC determination of several drugs in biological fluids and especially in plasma. The sample preparation is normally carried out using the ASTED (Automated Sequential Trace Enrichment of Dialysates) system connected on-line with an LC system. Chiap et al. describe such an automated procedure for the chromatographic determination of various chemicals (i.e. sotalol and human anesthetics) in human plasma. The method involves on-line dialysis, enrichment of the dialysate on a precolumn prepacked with a strong cation-exchange material, and subsequent LC analysis using UV detection. That described is among the first experiments where a combination of dialysis with the enrichment of the dialysate on a cationexchange sorbent was used. ${ }^{[33,34]}$

However, prior to the chromatographic analysis, complex samples may require multiple preparation techniques. For biological matrices, the complex of techniques may consist of deproteinisation of the plasma samples, liquid-liquid extraction after alkalinisation followed by back extraction in an acidic medium, as well as solid phase extraction on disposable cartridges after deproteinisation or alkalinisation. These are off-line procedures which are often performed manually and, therefore, are laborious and time-consuming. Under these circumstances, when the number of samples to be analyzed is particularly large, the automation of sample preparation often becomes a necessity. On-line automated LC procedures based on a column-switching technique or on-line sample preparation involving dialysis and trace enrichment on cation-exchange pre-columns have been recently developed. ${ }^{[33,34]}$ The trace enrichment system is incorporated to overcome the dilution of the sample caused by dialysis and to improve method selectivity.

In 2007, in an excellent review, Ridgway et al. treat many aspects of sample preparation. ${ }^{[12]}$ They refer to the determination of trace residues and contaminants in complex matrices, such as food, which often requires extensive sample extraction and preparation prior to instrumental analysis. The idea was to offer analysts with an excellent background in selecting suitable extraction and concentration methods which should move towards more environmentally friendly techniques, using less solvent and smaller sample sizes. In 2009, Nerin et al. are critically reviewing all recent developments in solventless techniques for the extraction of analytes in different areas. ${ }^{[63]}$ 


\section{Techniques available to increase selectivity and sensitivity}

A wide range of sample preparation techniques are presently available for the analysis of the three states of matter (gas, liquid and solid). Modern sample preparation techniques were developed and they gained more importance over conventional methods due to their major advantages, i.e. reduction in organic solvent consumption, improved clean-up procedures and concentration steps before chromatographic analysis, increase in extraction efficiency and selectivity. In this context, analysts' skills are completed by a full understanding of the theoretical aspects of equilibriums in liquid-liquid, liquid-solid, liquid-gas and gas-solid systems.

In the present paper, the sample preparation techniques for trace analysis by chromatographic methods have been classified considering two equilibrium types: liquidliquid or liquid-solid equilibriums, and gas-liquid or gas-solid equilibriums. This review considers most of the aspects of sample preparation for trace analysis by chromatographic methods. It covers general extraction techniques, such as liquid-liquid extraction, Soxhlet and pressurized liquid extraction, microextraction techniques such as liquid phase microextraction (LPME) and more selective techniques, such as solid phase extraction (SPE), solid phase microextraction (SPME) and stir bar sorptive extraction (SBSE), including their most recent developments and applications.

The theory of the extraction process is not covered in this review as this aspect is the subject of several books that treat comprehensive theoretical and practical aspects concerning sample preparation techniques in different research areas. ${ }^{[64-66]}$

\subsection{Derivatization}

Derivatization is a chemically driven process usually incorporated into an analytical method to facilitate chromatographic separation, to increase selectivity and to improve the limit of detection. Although numerous methods have been reported and several books cover the technique, only a few reactions are widely used in routine analysis. ${ }^{\text {[67,68] }}$

Most derivatization methods for gas chromatography involve esterification or etherification. For example, an analytical method has been developed to identify compounds containing one or more carbonyl, carboxy and hydroxy functional groups in atmospheric samples. In the method, $-\mathrm{C}=\mathrm{O}$ groups are derivatized using $\mathrm{O}-(2,3,4,5,6$ - pentafluorobenzyl $)$ hydroxy amine (PFBHA), and $-\mathrm{COOH}$ and $-\mathrm{OH}$ groups are derivatized using the silylation reagent N,O-bis(trimethylsilyl)- trifluoroacetamide (BSTFA) ${ }^{\left[{ }^{69-72]}\right.}$ Derivatization can also be performed on fibre/coatings before, during or after sorptive extractions. ${ }^{\text {[73] }}$

Derivatizations for HPLC are designed mainly to improve the limit of detection, permitting the use of highly sensitive or selective detectors inapplicable to the analytes themselves. Enhanced absorption of UV-visible light is achieved by the introduction of 
chromophoric groups. Analytes can also be rendered fluorescent by the introduction of fluorophoric groups.

Carboxylic acids can be transformed into esters that absorb UV or visible light by reacting with 1-naphthyldiazomethane ${ }^{[74]}$ or bromophenacyl bromides ${ }^{[75]}$. $\alpha$-Keto acids (e.g., glycolic, glyoxylic acids) are detectable with UV light after derivatization with 2,4dinitrophenylhydrazones. ${ }^{[76]}$ Fluorescent compounds are obtained by reacting carboxylic acids with 4-bromomethyl-7-methoxycoumarin ${ }^{[77]}$ or 4-hydroxymethyl-7-methoxy-coumarin ${ }^{[78]}$. Analytes containing hydroxyl groups, such as phenols, glycols, and alcohols, can be converted with 3,5-dinitrobenzoyl chloride into compounds that absorb UV or visible light. ${ }^{\text {[79] }}$ Fluorescent derivatives can be obtained with 7-[(chlorocarbonyl)methoxy]-4methylcoumarin. ${ }^{[80]}$ Derivatizations for HPLC purposes are accomplished either off-line or on-line. An on-line process may involve either pre-column or post-column reaction, depending on the analyte under consideration and the adopted instrumentation. In the case of pre-column derivatization, it is essential to check its compatibility with the separation process.

\subsection{Separation and enrichment techniques driven by liquid-liquid or liquid-solid equilibriums}

\subsubsection{Liquid-liquid extraction}

Liquid-liquid extraction is one of the most common methods of extraction, particularly for organic compounds from aqueous matrices. It is a simple, manual and off-line extraction procedure, used almost exclusively in the 1980s. It involves extraction of analytes in solution or liquid samples by direct partitioning with an immiscible solvent. Repeated extractions might ensure the complete partitioning of the interest analyte into the required phase. Cleanup or analyte enrichment/concentration steps, prior to instrumental analysis, may help for trace level analysis and improve the selectivity of the whole method. ${ }^{[1,82]}$

The major disadvantage of liquid-liquid extraction is the need for large volumes of organic solvents; the formation of emulsions may represent a relatively frequent problem. ${ }^{[15]}$ In liquid-liquid extraction there is a tendency for compounds to adsorb on all phase boundaries, which can lead to the formation of emulsions and prevent a complete phase separation. In some cases, to avoid emulsions, salt may be added and centrifugation or freezing can be used if necessary. ${ }^{[12,83]}$

The demixing/microextraction approach is very appropriate for GC-MS analysis as it is a procedure that avoids the imprecise solvent evaporation steps. It can be applied to waterethanol mixtures (e.g. wine) and consists of the separation between water and ethanol, achieved by addition of salts, followed by microextraction of the analytes from the ethanolic phase. Extraction is performed at laboratory temperature, ultra high purity solvents are not 
required and the final extract can be cleaned enough if the extraction conditions are correctly chosen. ${ }^{[1]}$

Within the liquid-liquid extraction process, the decisive parameter is the distribution coefficient for the analyte between the particular phases involved. If the distribution coefficient is sufficiently large, the simplest approach to liquid-liquid extraction is shaking the sample with an appropriate amount of an organic solvent. The distribution coefficient can be $\mathrm{pH}$ dependent, dividing the sample into strongly or weakly acidic, neutral, or basic fractions. ${ }^{[84]}$

With smaller distribution coefficients or large sample volumes, continuous extraction or countercurrent extraction is required to achieve a complete separation. The apparatus for continuous extraction causes a liquid immiscible with the sample solution to circulate continuously through the sample. ${ }^{[85]}$ Extracted analytes are concentrated by distillation at appropriate times between individual extraction cycles.

More recently, classical liquid-liquid extractions have been replaced by modern, efficient and versatile microextraction techniques. The time needed to reach equilibrium and the volume of solvent needed for the quantitative recovery of analytes switch the preference toward more modern methods. They are more and more frequently adopted both in organic synthesis laboratories and for the separations of metal complexes, metal chelates, and/or ionpairing reagents.

Although old in fashion, a variant of liquid-liquid extraction takes advantage of a liquid phase immobilized on a solid sorbent such as kieselguhr, Celite, Chromosorb W, or Chromosorb $\mathrm{P}^{\left[{ }^{86]}\right.}$ In this method the immobilized phase may be either aqueous or nonaqueous.

An "in-line" liquid-liquid extraction (LLE) system is created in hydrophilic interaction chromatography (HILIC), where the mobile phase forms a water-rich layer on the surface of the highly polar stationary phase. The mechanism involves distribution of the analytes between the water-rich stationary layer and the mobile phase with mostly organic content. The analytes possessing higher polarity will have a higher affinity to the stationary aqueous layer than the analytes possessing weaker polarity. As HILIC requires a high-organic and low-aqueous mobile phase, which are favorable conditions for MS in terms of sensitivity, HILIC appears to be a preliminary preparative step in MS analysis. ${ }^{[21]}$ A technical and cost effective method for a therapeutic drug monitoring program of ribavirin (a synthetic purine analogue of guanosine, used in the standard treatment of chronic hepatitis $\mathrm{C}$ virus) proposes hyphenation of a liquid/liquid extraction method coupled with HPLC-UV measurements. ${ }^{\text {[87] }}$

\subsubsection{Soxhlet extraction}

Soxhlet extraction, a liquid-solid equilibrium technique, has application in sample preparation prior to chromatographic analysis. It is basically a leaching technique based on two processes: 
reflux boiling of a solvent and a siphon procedure. This technique has been already reviewed. ${ }^{[88,89]}$ Recent developments have included the use of focused microwave-assisted extraction; ultrasonic extraction has been used to improve extraction efficiencies. ${ }^{[90,91]}$

The large volume of solvent which is needed for the sample extraction, the extra step required to concentrate the sample after solvent evaporation, the lack of thermal stability and volatility of some sample analytes, and interference from contaminants in the extraction thimbles (requiring a blank extraction prior to sample extraction) limit the application of this technique. Although exhaustive, the Soxhlet technique is not selective and further clean-up is necessary. Due to the temperatures involved, Soxhlet extraction can degrade thermally labile compounds. ${ }^{[89]}$ Many applications of Soxhlet extraction are for environmental samples, such as soil, but it has been used for the analysis of food followed by further clean-up. ${ }^{[88,92,93]}$

Automated Soxhlet extraction systems are available, that claim to greatly reduce extraction times and perform boiling, rinsing and solvent recovery automatically. Up to 6 samples can be extracted simultaneously and lower volumes of solvent can be used.

\subsubsection{Ultrasound-assisted extraction (USE)}

Ultrasound-assisted extraction (USE) is among the easiest and most reliable of the wide range of available extraction techniques. ${ }^{[94]}$ Ultrasound assistance is a growing trend in analytical chemistry. ${ }^{[95]}$ The technique is performed statically and utilizes energy in the form of acoustic sound waves to accelerate mass transport from a solid sample immersed in a solvent. The extraction setup is uncomplicated. Normally, an ultrasonic bath filled with water and a number of extraction vessels together with a relatively strong solvent or mixture, with appropriate properties for the targeted analytes and matrix, can be selected to obtain maximum extraction efficiency and required selectivity. ${ }^{[96]}$ This is a fast technique but efficiency is not as high as with other techniques. Low concentrations of analytes in samples require multiple extractions. Several extractions can be performed simultaneously. The technique is relatively inexpensive compared to most modern extraction methods, because no specialized laboratory equipment is required. One important disadvantage of ultrasoundassisted extraction is that it is not suitable for volatile analytes.

Herrera and Luque De Castro in 2005 used an ultrasound-assisted extraction technique followed by HPLC for the analysis of phenolic compounds from strawberries ${ }^{[97]}$ and Rezic et al., the same year, used ultrasound-assisted extraction and thin-layer chromatography for the determination of pesticides in honey ${ }^{[98]}$. Kimbaris et al. performed a comparison of distillation and ultrasound-assisted extraction methods for the isolation of aroma compounds from garlic. ${ }^{[99]}$ Other applications of the USE technique include extraction of polycyclic aromatic hydrocarbons (PAHs) from lichen samples, ${ }^{[100]}$ determination of polyphenols in tobacco, ${ }^{[101]}$ determination of butyltin and phenyltin species in sediments, ${ }^{[102]}$ determination of organophosphorus pesticides in sludge, ${ }^{[103]}$ and determination of triazine herbicide residues in 
horticultural products ${ }^{[104]}$. However, as both selectivity and sample enrichment capabilities are limited, further clean-up and/or concentration steps are usually required for the determination of trace analytes in several matrices. ${ }^{[104,105]}$

\subsubsection{Microwave-assisted extraction (MAE)}

In recent years, microwave-assisted extraction (MAE) has attracted growing attention as it allows rapid extraction of solutes from solid matrices, with extraction efficiency comparable to that of the classical techniques. ${ }^{[106,107]}$ Accelerated dissolution kinetics is produced in MAE as a consequence of the rapid heating processes that occur when a microwave field is applied to a sample. Microwave-assisted extraction gained enlarged attention due to its applicability to a wide range of sample types, because the selectivity can be easily manipulated by altering solvent polarities. ${ }^{[108]}$ There are studies suggesting that MAE affords a lower solvent consumption than pressurized liquid extraction (PLE, vide infra). ${ }^{[109]}$

An overview of the different microwave-based devices used for solid sample pretreatment has been published in 2003. ${ }^{[110]}$ The authors described multi-mode and focused microwave devices, as well as closed and open systems. Special open systems, such as a microwave-ultrasound combined reactor, a focused microwave-assisted Soxhlet extractor, a microwave-assisted dryer and a microwave-assisted distiller are discussed. Finally, there are brief comments on microwave-assisted robotic methods, and closed and open microwave systems are compared.

Because of its applicability to solid, semi-solid, and liquid matrices, microwave-assisted (MAE) extraction has emerged as a powerful sample preparation technique. It is only applicable to thermally stable compounds due to the increase in temperature during extraction. Although MAE can be used also for leaching purposes, its power in sample solubilization is nowadays mostly used for samples dissolution/digestion.

The main applications of MAE are as an alternative to Soxhlet extraction because good extraction efficiencies can be achieved using less solvent and shorter extraction times. ${ }^{[111]}$ Most publications to date have been for environmental applications, although Hermo et al. present the comparison between two analytical methods used for the determination of quinolones in pig muscle. ${ }^{[12]}$ The procedures involve the extraction of the quinolones from the tissues by traditional extraction and using microwave assisted extraction (MAE), a step for clean-up and preconcentration of the analytes by solid phase extraction, and subsequent liquid chromatographic separation with UV absorbance detection. In that study, ${ }^{[112]}$ microwaveassisted extraction (MAE) has proven to be an alternative to classical extraction because less interfering substances were observed and cleaner extracts were obtained. As with Soxhlet extraction, further extraction or clean-up steps such as solid phase extraction (SPE) are generally required, particularly for the determination of trace contaminants. ${ }^{[113]}$ 


\subsubsection{Accelerated solvent extraction (ASE)}

Accelerated solvent extraction (ASE), sometimes referred to as pressurized liquid extraction (PLE) or pressurized fluid extraction (PFE), may be used for solid and semi-solid samples. The elevated temperatures and pressures used in these techniques are causing reduction in dipole interactions and hydrogen bonds, increasing the surface wetting. ASE has the advantage that water may also be used as solvent, if it is below the critical point.

Because often a large number of samples need to be analyzed, methods to speed up the extraction process have been widely examined. ASE involves extraction with liquid solvents, but at elevated temperatures and pressures. In ASE, the sample is heated in the presence of an extraction solution at high pressures, up to 2000 psi. Like the closed-vessel microwave approach, this technique utilizes the fact that liquids at elevated pressure can be heated to temperatures above their respective boiling points without transition to the gaseous phase. Several other names have been used for this technique, including pressurized fluid extraction PFE, high-pressure solvent extraction - HPSE, high-pressure, high temperature solvent extraction - HPHTSE, pressurized hot solvent extraction - PHSE, and subcritical solvent extraction - SSE. Carabiaz-Martinez et al. reviewed the distinct advantages of this technique exploited in several areas, including biology and the pharmaceutical and food industries. ${ }^{[14]}$ A relatively new variant of ASE switches the usual procedure to superheated water extraction when water is used as a solvent. A review of the technique, including several applications was given recently by Smith. ${ }^{[15]}$

ASE provides faster extractions than conventional Soxhlet techniques, because of the accelerated desorption of analytes from the matrix and the more rapid kinetic processes for dissolution. ${ }^{[116,117]}$ In the case of most organic solvents, diffusion rates increase exponentially with temperature. Due to the lower viscosity and higher diffusivity of the solvent, mass transfer into the extraction solvent is faster. The higher temperatures also make it easier for the solvent to overcome intermolecular interactions of the analyte and matrix effects.

The nature of the extraction procedure in ASE is both static and dynamic. The procedures may involve a certain number of extraction cycle(s), the extraction cell being flushed with a pre-determined volume of fresh solvent and then purged with nitrogen gas $\left(\mathrm{N}_{2}\right)$ in order to recover all of the extraction solvent and analyte.

In specific applications, further clean-up is usually required for some target analytes. Sometimes the clean-up step can be done "in situ", by adding sorbent materials or a desiccant (e.g. sodium sulphate) directly to the extraction cell. When the "in situ" clean-up procedure is not strictly required, after performing ASE it is possible to use a typical sorbent to produce the cleanest extracts for target samples from the initial extract. ${ }^{[18]}$ Other clean-up steps coupled with the ASE technique and their details can be found in the literature. ${ }^{[84,91,119-121]}$

Preliminary ASE, with non-polar solvents to eliminate the hydrophobic compounds prior to the extraction of the analytes of interest, represents an alternative approach. There are some 
situations when elevated temperatures and pressures are not enough to dissolve analytes from a complex matrix. In such a case, modifiers (e.g. sodium dodecyl sulphate) can be added to the extraction solvent. ${ }^{[122]}$

The application of ASE as a sample preparation technique for the analysis of matrix components in food and biological samples has been already reviewed in $2005 .{ }^{[114]}$ Since then, many other applications of this technique for the determination of organic analytes from different matrices have been published. ${ }^{[123-127]}$

\subsubsection{Subcritical water extraction (SWE)}

In the last few years there has been an interest in the use of water as the solvent for pressurized liquid extraction as this can reduce or eliminate the use of organic solvents. ${ }^{[128]}$ This technique usually adopts water in the condensed phase between $100{ }^{\circ} \mathrm{C}$ and the critical point, and it is generally referred to as superheated water extraction (SHWE). It has also been called subcritical water extraction (SWE), hot water extraction (HWE), pressurized hot water extraction (PHWE) or high temperature water extraction (HTWE). SHWE is cleaner, faster, cheaper and more environmentally friendly than conventional methods.

Water is unique due to its high level of hydrogen-bonding, giving it a high boiling point and high dielectric constant and polarity. As the temperature of water is increased (under pressure), the polarity decreases and therefore extraction becomes more selective. At 100$374{ }^{\circ} \mathrm{C}$ it can act as a medium/non-polar solvent. ${ }^{[129]}$ The useful temperatures and pressures of water for SWE are lower than the critical point, in contrast to super-critical fluid extraction (SFE) with carbon dioxide. A review of the SWE technique, including several applications was given by Smith in $2006^{[115]}$ and more recently in $2008^{[129]}$. Most applications to date are for solid samples, such as soil, and include the determination of selected polycylic aromatic hydrocarbons (PAHs), polychlorobiphenyls (PCBs) and pesticides.

\subsubsection{Supercritical fluid extraction}

Supercritical fluid extraction (SFE) is a technique which became very popular during the 1980s. ${ }^{[130]}$ Generally speaking, supercritical fluids (SFs) are gases with high density above their critical temperature and pressure that exhibit simultaneously properties associated with both gases and liquids. ${ }^{[131-133]}$ Thus, like gases, they are compressible, but they also display solvencies similar to those of the liquids.

As the name suggests, supercritical fluid extraction (SFE) employs supercritical fluids for extraction purposes in place of the organic solvents of conventional extraction. Any increase in temperature at constant pressure reduces the solvent power of a supercritical fluid, but it also leads to an increase of the diffusion rate, which tends to lower the minimum required extraction time. Compared to conventional extractants, supercritical fluids have low viscosity and have diffusion rates that are higher by a factor of 10 to 100 , both of which contribute to 
reduce the extraction times. Moreover, analyte melting points and solubility in the SF are important properties to consider. ${ }^{[132]}$ With supercritical $\mathrm{CO}_{2}$ and $\mathrm{N}_{2} \mathrm{O}$, which are gases under normal conditions, the extractant is separated by reducing the pressure to atmospheric levels, leading to simultaneous concentration of the extract.

Supercritical $\mathrm{CO}_{2}$ is the most frequently used extractant for SFE. It has recoverable characteristics and the ability to solubilize lipophilic substances. ${ }^{[134,135]}$ It has the advantage of being chemically rather inert. Its critical temperature is low, so it is acknowledged as a valuable chemical for the extraction of thermolabile analytes such as steroids and fragrances. ${ }^{[136]}$ Other advantages of $\mathrm{CO}_{2}$ as an extractant include high purity and low cost. The principal disadvantage of $\mathrm{CO}_{2}$ is a relatively low polarity. However, its solvent power with respect to polar analytes can be improved by adding polar modifiers (or a mixture of them) such as methanol and n-hexane, ${ }^{[137]}$ ethanol, ${ }^{[138]}$ aqueous acetonitrile ${ }^{[139]}$, or dichloromethane ${ }^{[140]}$.

Extraction with supercritical $\mathrm{CO}_{2}$ has been used for separating a wide variety of analytes, including pesticides from food, ${ }^{[141]}$ vegetables, ${ }^{[142]}$ aquaculture and marine environmental samples, ${ }^{[143]}$ vitamins from tablet matrices,${ }^{[144]}$ PCBs from fish muscle, ${ }^{[145]}$ sediments ${ }^{[146,147]}$ and powdered full-fat milk ${ }^{[148]}$.

\subsubsection{Solid-phase microextraction (SPME)}

Solid phase microextraction (SPME) is a simple, rapid, sensitive and solvent-free sample preparation technique in which analytes in either air or water matrices are extracted into the polymeric coating of a fiber. ${ }^{[19]}$ It was originally developed by Arthur and Pawliszyn in $1990 .^{[149]}$ Subsequently a number of books have been written on the technique. ${ }^{[150-152]}$ The mechanism of SPME is based on the partitioning equilibrium of the analytes between the sample or the headspace above the sample, respectively, and a fused silica fiber coated with a suitable stationary phase. The amount of analyte extracted by the fiber is proportional to the initial analyte concentration in the sample and depends on the type of fiber. After sampling, the fiber can be thermally desorbed directly into the injector of a gas chromatograph. SPME combines sampling, analyte enrichment, matrix separation, and sample introduction within one step. ${ }^{[153]}$ Since its development, this innovative technique has found widespread use in environmental analysis. It has, for example, been applied in the determination of volatile organic compounds, ${ }^{[154]}$ biologically active substances, ${ }^{[155]}$ phenols, ${ }^{[156]}$ pesticides, ${ }^{[157]}$ polyaromatic hydrocarbons, and polychlorinated biphenyls ${ }^{[158,159]}$ in water. In a technical note it is presented the application of the SPME hyphenated with a temperature-programmed desorption (TPD) for the analysis of chemicals with wide-ranging volatilities without causing their thermal degradation. ${ }^{[19]}$ Degradation is, however, a problem often encountered also in the analysis of active pharmaceutical ingredients. Shepard et al. describe a complex 
preparation alternative for the analysis of L-ascorbic acid, a compound which can be degraded in the solid phase under the influence of moisture. ${ }^{[160,161]}$

SPME fibers have also been used as air sampling devices for volatile organic compounds in ambient and workplace air. The results obtained with SPME were in good agreement with traditional sampling methods. ${ }^{[162,163]}$

In a detailed review on SPME technique, fibers with different thickness and polarities are presented. ${ }^{[164]}$ Many examples of SPME applications, including direct immersion into a liquid sample and headspace sampling are presented in a review of food analysis. ${ }^{[165]}$ However, direct immersion of SPME into some natural matrices can be difficult and the fiber can be damaged or some analytes can adsorb irreversibly to the fiber, changing its properties and making it unusable for more than one sample. The use of SPME-LC for the analysis of pesticides was reviewed in 2005. ${ }^{[166]}$ In 2007 the most suitable sample preparation techniques for organic compounds in air and water matrices were also reviewed. ${ }^{[167]}$

The main advantages of the SPME technique compared to solvent extraction include the reduction in solvent use and also the sensitivity for polar and non-polar analytes in a wide range of matrices, when SPME is combined with both GC and LC. The main disadvantage of the SPME is the low storage stability of the samples, due to uncontrolled losses of analytes by adsorption or by evaporation from the loaded fiber.

A recent development of the SPME technique is the new superelastic fiber type. This is a metal alloy with elastic properties that can be coated with polydimethylsiloxanedivinilbenzene (PDMS/DVB), carboxen/PDMS and DVB/carboxen-PDMS as well as PDMS. This alternative improves the robustness and overcomes the problems of the breaking of fibers due to misalignment with injection ports or in viscous matrices. ${ }^{[168]}$ Two relatively new reviews include discussion of recent developments that may have significant implications for automation, such as superelastic fiber assemblies and internally cooled fiber-SPME. ${ }^{[169,170]}$ These reviews also describe the recent developments of solid-phase microextraction technology applied to food, environmental and bioanalytical chemistry.

\subsubsection{Stir bar sorptive extraction (SBSE)}

Stir bar sorptive extraction (SBSE) technique is a sample preparation tool based on sorptive extraction of interest analytes that can later be removed by thermal desorption in the gas chromatographic injection port. SBSE is a dynamic variation of SPME in which a spinning glass-covered magnetic bar (coated with a thick layer of polydimethylsiloxane) is used to sorb. This technique was developed in 1999 using stir bars coated with 50-300 $\mu$ l of polydimethylsiloxane (PDMS). ${ }^{[171]}$ The advantage of SBSE is a higher enrichment factor combined with the application range and extraction mechanism of SPME. ${ }^{[172]}$ Transfer of the analyte from the bar is achieved either by GC thermal desorption, or by elution with an LC solvent. As with SPME, the stir bar can also be used to sample the volatiles and semi-volatiles 
in the headspace above the sample. It can be used for liquid or semi-solid complex matrices and therefore has potential for many applications in coffee brew analysis ${ }^{[173]}$, in the determination of polycyclic aromatic hydrocarbons (PAH) in aqueous samples ${ }^{[174]}$ and for the determination of pesticide residues in honey. ${ }^{[175]}$

There are several articles that compare SBSE with other extraction technique on different target analytes. Steam distillation extraction, ${ }^{[176]}$ membrane assisted solvent extraction $(\mathrm{MASE})^{[177]}$ and SPME ${ }^{[178]}$ represent some alternative extraction techniques used in different studies, in which the authors concluded that SBSE is more sensitive and affords improved reproducibility and less artifact formation. However, despite good sensitivity, SBSE extraction was not suitable for the analysis of some polar pesticides in food. ${ }^{[179]}$ David et al. gave examples of food analysis by using the SBSE technique, and described the analysis of solid samples after an initial extraction with a water-miscible solvent. ${ }^{[180]}$

Because of the PDMS coating, SBSE is most suitable for the analysis of non-polar analytes from aqueous media. To a lesser extent it can be concluded that this technique can be used for more polar compounds after a proper derivatization step. Bicchi et al. describe how to improve the recovery of more polar analytes in SBSE and HSSE (HeadSpace Sorptive Extraction) techniques. ${ }^{[173]}$ Applications of SBSE in analysis are increasing, but due to the limitations of the PDMS phase they are still currently limited to non-polar or semi-polar analytes. ${ }^{[181]}$

\subsubsection{Hollow fiber membrane extraction}

The demand for automation in analytical liquid-liquid extraction (LLE) combined with organic solvent reduction or elimination has led to the recent development of liquid-phase microextraction (LPME) based on disposable hollow fibers. ${ }^{[182]}$ This approach has been reviewed by Rasmussen and Pedersen-Bjergaard. ${ }^{[183]}$ This review focuses on basic extraction principles, technical set-up, recovery, enrichment, extraction speed, selectivity, applications, and future trends in hollow fiber-based LPME. In this technique, analytes of interest are extracted from aqueous samples, through a thin layer of organic solvent immobilized within the pores of a porous hollow fiber, into an acceptor solution inside the lumen of the hollow fiber. Subsequently, the acceptor solution is directly subjected to a final analysis by capillary gas chromatography (CGC), high-performance liquid chromatography (HPLC), capillary electrophoresis (CE), or mass spectrometry (MS) without any further effort. Hollow fiberbased LPME may provide high analyte pre-concentration and excellent sample clean-up, and it has a broad application potential within areas such as drug analysis and environmental monitoring. A simple and easy-to-use extraction procedure has been applied for the extraction of 2-amino-1-methyl-6-phenylimidazo[4,5-b]pyridine (PhIP) in urine and spiked plasma samples, using a short piece of narrow capillary-like microporous hollow-fibre (HF) membrane as extraction device. ${ }^{[184]}$ 


\subsection{Enrichment techniques driven by gas-liquid or gas-solid equilibriums}

The rapidly developing trend of chromatographic analysis foresees the use of the substance to be analyzed as one of the phases of the heterogeneous (usually) gas-liquid system. The analytical and physico-chemical characteristics of the liquid phase (and sometimes solid) are determined by analyzing the gaseous phase into which some part of the components of the liquid material to be analyzed is partitioning with the establishment of an equilibrium. The name of the method, "analysis of equilibrium vapor" or "vapor-phase analysis" (head-space analysis, HSA) is derived from this equilibrium condition. ${ }^{[185]}$ However, it must be noted that the thermodynamic equilibrium between the phases is not required in all the practical applications. Accordingly, there are possible methods of determination that assume only a certain degree of equilibration. A distinctive feature of the HSA technique is that the chemical information contained in the gas phase is used to determine the nature and composition of the condensed phase with which it is in contact. The development of HSA methods opens up wide possibilities for determining trace contaminants in the atmosphere, in other gaseous media, and in other substances. The features of HSA make it a very effective technique. Two groups of methods of head-space analysis can be distinguished, namely: static methods when the equilibrium between the gas and the condensed phases is reached within a closed system, and dynamic methods. In the latter, the contact between the phases occurs in an open system in which a flow of gas is passed through a layer of liquid sample or a granulated solid phase, and the volatile analytes (or their derivatives) are purged out of the system.

\subsubsection{Static headspace technique}

The classical HSA methods (including their automated variations) are based on sampling the volatile analytes from an enclosed space in a static system using a gas-tight syringe. Analytes of interest are equilibrated in a closed vial at a specified temperature and pressure. Use of a gas-tight syringe (or autosampling system) is one of the common techniques used to transfer the headspace sample into the gas chromatograph.

HSA is considered to be a technique directly connected with a gas chromatographic analytical instrument, but it can be used with practically any analytical technique. In fact the first applications of headspace sampling were not in GC. ${ }^{[185]}$ The main disadvantage of static headspace extraction is the lack of preconcentration. Consequently this technique is not fully suitable to the analysis of trace and ultra-trace constituents, unless the loss (or the lack of gain) in sensitivity during extraction is compensated by the detection technique.

A brief overview of headspace analysis techniques and the underlying theory has been provided by Snow and Slack in 2002. ${ }^{[186]}$ The paper includes examples of applications in environmental, clinical, forensic, biological, food, flavor and pharmaceutical analysis. 
Headspace-single-drop microextraction (SDME) is a variation on static headspace. Volatile components are trapped on a single drop of solvent that is suspended from the tip of a syringe in the headspace above the sample. Practical difficulties with the technique include a limited choice of solvents due to viscosity requirements, and further work is needed to prove the reproducibility of this technique. ${ }^{[187]}$

Most of the papers related to HS-SDME deal with the determination of trace polycyclic aromatic hydrocarbons in environmental samples, ${ }^{[188]}$ the analysis of carbonyl compounds in biological and oil samples after derivatization with 2,4,6-trichlorophenylhydrazine (TCPH) ${ }^{[189]}$ and the analysis of volatile halocarbons. ${ }^{[190]}$ Lambropoulou et al. (2007) published an analytical application of HS-SDME, which was adopted as an isolation and trace enrichment step prior to the analysis of organic pollutants (pesticides, polycyclic aromatic hydrocarbons, polychlorinated compounds, organotin compounds, phenolic derivatives, aromatic amines, phthalates, etc.) by gas and liquid chromatography. ${ }^{[191]}$

Headspace-solid phase microextraction (HS-SPME) is another variation on static headspace that traps the volatile components onto a SPME fiber held above the sample. Such mode of extraction is based on the equilibriums between three phases: sample matrix, vapor phase and fiber. Interestingly, in conventional headspace analysis raising the temperature increases the amount of analyte in the vapor phase and hence gives improved sensitivity. In contrast, with HS-SPME a higher temperature may result in less deposition onto the fiber as volatile components again favor the vapor phase. In some cases the peculiar features of HSSPME can make a definite advantage: in studying the aroma profile of cocoa products, the fiber was proved to be more favorable for the enrichment of lower volatility compounds than the direct headspace. ${ }^{[192]}$ HS-SPME was also used for the determination of pesticide residues in fruits and vegetables ${ }^{[193]}$ and for the analysis of trihalomethanes in water samples ${ }^{[194]}$.

\subsubsection{Dynamic headspace technique}

Dynamic headspace is basically a development of the static headspace so that complete removal of the volatile analyte from the HS is accomplished. In principle, the volatile analytes are stripped out of the solution by a carrier gas and then subjected to a pre-concentration step by trapping them on various media. It usually follows a thermal desorption into a gas chromatograph. Such an approach is involving on the one hand the purging of the analytes and on the other hand their trapping, and is generally called purge-and-trap injection (PTI).

The major drawback of the dynamic headspace is the limitation to the analysis of relatively volatile compounds with boiling points below $200{ }^{\circ} \mathrm{C}$. Also, this technique is expensive and requires a fully dedicated and complex instrument.

Several experimental designs have been developed as trap devices. The needle capillary adsorption trap device, described by McComb et al., is based on a combination of SPME and purge and trap methods. ${ }^{[195]}$ Only limited applications of such SPME devices in dynamic 
headspace analysis have been published, such as the determination of volatile compounds from aqueous ${ }^{[196]}$ or gaseous samples. ${ }^{[197]}$

A recent development in headspace analysis is solid phase dynamic extraction, also called headspace-solid phase dynamic extraction (HS-SPDE). In this technique the headspace is repeatedly drawn up into a syringe, through a coated needle which traps the analytes. The latter are then desorbed directly into a GC. A variety of sorbents is available including divinylbenzene, carboxen, carbowax, polyacrylate and mixed phases. This technique has been applied for the trace determination of volatile or semi-volatile analytes in aqueous matrices ${ }^{[198]}$ or in food matrices. ${ }^{[199]}$

\subsubsection{Solid phase extraction (SPE)}

This technique is used for the selective separation and concentration of analytes from liquid or gas samples, and often is used to clean up and concentrate liquid extracts. Therefore, SPE could have been included in Paragraph 5.2 as well. SPE is a technique referring to a nonequilibrium exhaustive removal of analytes (semi-volatiles and non-volatiles) from a liquid sample by retention on a solid phase (sorbent), and to the subsequent elution of selected analytes from the solid phase by an appropriate solvent. ${ }^{[65]}$ The desorption of the analytes from the solid phase can also occur under thermal treatment. The efficient use of this technique requires optimization of the sorption and desorption processes.

Extraction by SPE is based on the distribution of the analytes between the sample and a solid phase, which is usually contained in a cartridge. Separation of target analytes from complex matrices may be a sum of several synergic effects such as differing polarities, differences in molecular size, and differences with respect to ion-exchange capacity.

Solid-phase extraction (SPE) has several advantages over liquid-liquid extraction (LLE). SPE can be accomplished more rapidly, requires less solvent and provides more highly concentrated extracts. It is possible to choose among a range of adsorbents that use different mechanisms for the extraction/retention of analytes. The different adsorbents that are applicable in the SPE technique can be classified according to their nature as nonpolar (e.g. those carrying octadecyl, octyl, butyl, cyclohexyl, phenyl, amino and diol groups), polar (e.g. cyano, Kieselguhr, silica gel, Florisil, aluminum oxide), anion exchangers (e.g. primary amine, secondary amine, quaternary ammonium salt) and cation exchangers (e.g. carboxylic acid, sulfonic acid). The most common adsorbents for solid-phase extraction are based on silica gel, the surface of which has been modified in some way. ${ }^{[200]}$

Octadecyl surface solid-phase (C18) is used for the reversed-phase extraction of nonpolar substances from aqueous solutions. Typical applications include the extraction of organochlorine pesticides, ${ }^{[201]}$ organophosphorus pesticides, ${ }^{[202]}$ chlorinated hydrocarbons, ${ }^{[203]}$ PAHs, ${ }^{[204]}$ phenols and chlorophenols ${ }^{[205]}$ and antibiotics. ${ }^{[206]}$ Octyl surface solid-phase $(\mathrm{C} 8)$ is 
used for extracting substances of medium polarity. Substances that bind irreversibly to $\mathrm{C} 18$ phases can often be concentrated and re-eluted successfully with $\mathrm{C} 8$ phases.

Unmodified silica gel, aluminum oxide and Florisil, usually called normal phase materials, separate sample constituents into fractions of comparable polarity. They are often utilized to separate and concentrate pesticides, ${ }^{[207]} \mathrm{PCBs},{ }^{[208]}$ polychlorodibenzodioxins and dibenzofurans $(\mathrm{PCDD} / \mathrm{PCDFs})^{[209]}$ and for the simultaneous determination of bisphenol A, triclosan and tetrabromobisphenol $\mathrm{A}^{[210]}$ from biological, agricultural and environmental samples.

Normal phases are also used to extract polar sample constituents, such as amines, alcohols, phenols, dyes, medicaments, or vitamins. ${ }^{\text {[211,212] }}$

Apart from modified silica gel, the most frequently used solid-phase adsorbents are activated charcoal and resins (XAD). Activated charcoal is a universal adsorbent for concentrating trace organic materials from aqueous solutions and air. XAD resins are also commonly employed for extracting organic trace constituents, such as persistent organic pollutants from the atmosphere. ${ }^{[213]}$

The activity of these solids must be accurately adjusted to ensure reproducible results and well-defined fractions. One of the drawbacks of SPE is that the packing must be uniform to avoid poor efficiency. The sample matrix can also affect the ability of the adsorbent to extract the analyte due to competition for retention. The limits of many traditional adsorbents in terms of selectivity and insufficient retention of very polar compounds can also be a problem. ${ }^{[214]}$

A recently developed variant of SPE is the extraction with synthetic molecularly imprinted polymers (MIPs). Thus, retention of analytes on the adsorbent is due to shape recognition in the cavities or imprints. Due to the nature of their selectivity, synthetic MIPs can often be used for a number of matrices, even though the interaction may be different. ${ }^{[215]}$ They can be heated and are stable in both organic solvents and strong acids and bases. However, custom-made products must be prepared for each analyte. Moreover, stringent cleaning of the MIP, prior to trace analysis, is necessary to remove the analyte, which had been used as a template. MIPs have been used as selective adsorbents for a range of analytes and matrices. ${ }^{[216]}$

As already discussed, SPE is a useful clean-up technique for trace analysis but, usually, it is not employed alone for sample preparation. SPE would rather follow an initial extraction step. Selective adsorbents in SPE are a useful tool for both selective and sensitive analysis of trace contaminants in complex matrices. 


\section{Conclusions}

Detection methods are becoming more specific and sensitive. In trace analysis, sample preparation is particularly important as it can account for a significant amount of the variability of a particular method. Thus, sample preparation is a critical step in the overall process of obtaining reliable and accurate data, especially in the trace analysis of nonvolatile and semi-volatile organic compounds. Considering the large number of articles published in the last decade, it can be easily concluded that trends in sampling preparation are focused on the minimization of the use of organic solvents in, automation of, and speeding up of the sample preparation procedure. Some guiding principles can be given depending on the purpose of the analysis, the available amount of sample, the required sensitivity, and the type of sample matrix and analytes to be investigated.

For liquid and solid samples, SPME and SBSE combined with gas chromatographic analysis are good options when the target analytes are nonpolar and volatile. The two extraction methods can also be used for analyzing volatile compounds from solid samples, but only when combined with the dynamic head space technique.

For polar analytes, SPE and LPME are suitable. The big advantage of miniaturized SPE extraction is the minimum amount of sample and organic solvent required, but sensitivity is lower. However, SPE techniques are exhaustive extraction and purification methods, and are suitable for quantitative analysis as well. MAE, also, can be used for the extraction of liquid samples.

For the analysis of volatile compounds, head-space extraction combined with SPME or SBSE are simple and direct options. However, for semi-volatile compounds more exhaustive methods are probably needed.

Nowadays, ASE is gradually replacing Soxhlet extraction. ASE is a good method for the extraction of tightly bound compounds in samples such as sediment and soil. The disadvantage of the ASE extracts is that they typically contain a large amount of undesirable matrix components. Accordingly, a clean-up step of the extract (e.g. by SPE) is always needed.

For samples in which the analytes are not very tightly bound to the matrix, e.g. food, biological tissues, plant and atmospheric aerosol particles, MAE and USE represent good extractions methods.

The trend of sample preparation is towards automated systems that can be integrated with the final separation step. Presently a few automated methods are available, and only for liquid samples. For solid and semisolid samples, fully automated systems are not available for routine analyses, although several interesting systems have been reported for special applications. For complex matrices, such as biological, environmental and food samples, a combination of different extraction techniques is often required. However, the objective of any chromatographic method should be to achieve the required performance (e.g. sensitivity, 
accuracy and precision) in as few steps as possible. Further development is needed to make such systems applicable to large-scale analysis.

\section{ACKNOWLEDGEMENTS}

R.I. Olariu wants to acknowledge here the financial support for research in the field under PN-II-ID PCE 2007 program, project No. 405, CNCSIS-UEFISCUS-ANCS. C. Arsene gratefully acknowledges financial support for research from the European Commission, under the project MERG-CT-2007, No. 203934 (ICAARUS).

\section{References}

1. Ullmann, F. Ullmann's Encyclopedia of Industrial Chemistry. Sample preparation for trace analysis. John Wiley\&Sons, $6^{\text {th }}$ edition, 2002.

2. Baltussen, E.; Cramers, C.A.; Sandra, P.J.F. Sorptive sample preparation - a review. Anal. Bioanal. Chem. 2002, 373, 2-22.

3. Hyotylainen, T. Critical evaluation of sample pretreatment techniques. Anal. Bioanal. Chem. 2009, 394, 743-758.

4. Fritz, J.S.; Dumont, P.J.; Schmidt, L.W. Methods and materials for solid phase extraction. J. Chromatogr. A 1995, 691, 133-140.

5. Szpunar, J. Bio-inorganic speciation analysis by hyphenated techniques, Analyst 2000, 125, 963-988.

6. Vanhoenacker, G.; Dumont, E.; David, F.; Baker, F.; Sandra, P. Determination of arylamines and aminopyridines in pharmaceutical products using in-situ derivatization and liquid chromatography-mass spectrometry. J. Chromatogr. A 2009, 1216, 3563-3570.

7. Guideline on the limits of genotoxic impurities, CHMP, June 2006, http://www.emea.europa.eu.

8. Report on toxicological profile for methylene chloride. U.S. Department of Health and Human Services, Public Health Service, Agency for Toxic Substances and Disease Registry, Atlanta, Georgia, 2000.

9. Alzaga, R.; Ryan, R.W.; Taylor-Worth, K. Lipczynski, A.M.; Szucs, R.; Sandra, P. A generic approach for the determination of residues of alkylating agents in active pharamaceutical ingredients by in-situ derivatization-headspace-gas chromatography-mass spectrometry. J. Pharm. Biomed. Anal. 2007, 45, 472-479.

10. Buchberger, W.W. Novel analytical procedures for screening of drug residues in water, waste water, sediment and sludge. Anal. Chim. Acta 2007, 593, 129-139. 
11. Ferreira, V.; Lopez, R.; Escudero, A.; Cachi, J.F. Quantitative determination of trace and ultratrace flavour active compounds in red wines through gas chromatographic-ion trap mass spectrometric analysis of microextracts. J. Chromatogr. A 1998, 806, 349-354.

12. Ridgway, K.; Lalljie, S.P.D., Smith, R.M. Sample preparation techniques for the determination of trace residues and contaminants in foods. J. Chromatogr. A 2007, 1153, 36-53.

13. Covaci, A.; Dirtu, A.C. Brominated flame retardants: Analytical, toxicological and environmental aspects. NATO Science for Peace and Security Series A: Chemistry and Biology. 2008, 153-184.

14. Wilkes, J.G.; Sutherland, J.B., Sample preparation and high-resolution separation of mycotoxins possessing carboxyl groups, J. Chromatogr. B 1998, 717, 135-156.

15. Vogt, C.; Heinig, K. Trace analysis of surfactants using chromatographic and electrophoretic techniques. Fresenius J. Anal. Chem. 1999, 363, 612-618.

16. Petrovic, M.; Barcelo, D. Analysis of ethoxylated nonionic surfactants and their metabolites by liquid chromatography/atmospheric pressure ionization mass spectrometry. J. Mass Spectrom. 2001, 36, 1173-1185.

17. Huie, C.W. A review of modern sample-preparation techniques for the extraction and analysis of medicinal plants. Anal. Bioanal. Chem. 2002, 373, 23-30.

18. Ali, I.; Gupta, W.K.; Aboul-Enein, H.Y.; Hussain, A. Hyphenation in sample preparation: Advancement from the micro to the nano world. J. Sep. Science 2008, 31, 2040-2053.

19. Frazey, P.A.; Barkley, R.M.; Sievers, R.E. Solid-phase microextraction with temperature programmed desorption for the analysis of iodination disinfection byproducts. Anal. Chem. 1998, 70, 638-644.

20. Zwiener, C.; Frimmel, F.H. LC-MS analysis in the aquatic environment and in water treatment - a critical review. Part I: Instrumentation and general aspects of analysis and detection. Anal. Bioanal. Chem. 2004, 378, 851-861.

21. Hsieh, Y. Potential of HILIC-MS in quantitative analysis of drugs and drug metabolites. J. Sep. Sci. 2008, 31, 1481-1491.

22. Maia, A.M.; Baby, A.R.; Yasaka, W.J.; Suenaga, E.; Kaneko, T.M.; Velasco, M.V.R. Validation of HPLC stability-indicating method for Vitamin $\mathrm{C}$ in semisolid pharmaceutical/cosmetic preparations with glutathione and sodium matabisulfite, as antioxidants. Talanta 2007, 71, 639-643.

23. Pauwels, A.; Wells, D.A.; Covaci, A.; Schepens, P.J.C. Improved sample preparation methods for selected persistent organochlorine pollutants in human serum using solidphase disk extraction with gas-chromatographic analysis, J. Chromatogr. B 1999, 723, 117-125. 
24. Hu, J.; Fu, L.; Zhao, X.; Liu, X.; Wang, H.; Wang, X.; Dai, L. Dispersive liquid-liquid microextraction combined with gas chromatography-electron capture detection for the determination of polychlorinated biphenyls in soils. Anal. Chim. Acta 2009, 640, 100-105.

25. Jacobsen, P.B. On-line dialysis and quantitative high-performance liquid chromatography analysis of iodixanol in human, rat and monkey plasma. J. Chromatogr. B 2000, 749, 135142.

26. Vinkovic, K.; Drevenkar, V. Ion chromatography of azide in pharmaceutical protein samples with high chloride concentration using suppressed conductivity detection. J. Chromatogr. B 2008, 864, 102-108.

27. Turnell, D.C.; Cooper, J.D.H. Automated sequential process for preparing samples for analysis by high-performance liquid chromatography. J. Chromatogr. 1987, 395, 613-621.

28. Liu, H.; Wehmeyer, K.R. Solid-phase extraction with supercritical fluid elution as a sample preparation technique for the ultratrace analysis of flavone in blood plasma. J. Chromatogr. 1992, 577, 61-67.

29. McCrossen, S.D.; Giles, R.G.; Oxley, P.W.; McArdle, J.V. High-performance liquid chromatography procedure for the determination of purity of di-N-n-propylamine. J. Chromatogr. 1992, 623, 229-235.

30. Lucock, M.D.; Green, M.; Priestnall, M.; Daskalakis, I.; Levene, M.I.; Hartley, R. Optimisation of chromatographic conditions for the determination of folates in foods and biological tissues for nutritional and clinical work. Food Chem. 1995, 53, 329-338.

31. Jagota, N.K.; Chetram, A.J.; Nair, J.B. Ion chromatography of amylamine and tertbutilamine in pharmaceuticals. J. Chromatogr. A 1996, 739, 343-349.

32. Lachatre, F.; Marquet, P.; Ragot, S.; Gaulier, J.M.; Cardot, P.; Dupuy, J.L. Simultaneous determination of four anthracyclines and three metabolites in human serum by liquid chromatography-electrospray mass spectrometry, J. Chromatogr. B 2000, 738, 281-291.

33. Chiap, P.; Ceccato, A.; Miralles Buraglia, B.; Boulanger, B.; Hubert, P.; Crommen, J. Development and validation of an automated method for the liquid chromatographic determination of sotalol in plasma using dialysis and trace enrichment on a cationexchange pre-column as on-line sample preparation. J. Pharm. Biomed. Anal. 2001, 24, 801-814.

34. Chiap, P.; Boulanger, B.; Fotsing, L.; Hubert, Ph.; Crommen, J. Liquid chromatographic analysis of local anesthetics in human plasma after sample preparation by on-line dialysis. Optimisation by use of experimental design. Chromatographia 2001, 53, 678-686.

35. Miao, X.S.; Metcalfe, C.D. Determination of pharmaceuticals in aqueous samples using positive and negative voltage switching microbore liquid chromatography/electrospray ionization tandem mass spectrometry. J. Mass Spectrom. 2003, 38, 27-34. 
36. Li, W. Trace analysis of residual methyl methanesulfonate, ethyl methanesulfonate and isopropyl methanesulfonate in pharmaceuticals by capillary gas chromatography with flame ionization detection. J. Chromatogr. A 2004, 1046, 297-301.

37. Gaca, J.; Wejnerowska, G. Determination of epichlorohydrin in water and sewage samples. Talanta 2006, 70, 1044-1050.

38. Ceccato, A.; Toussaint, B.; Chiap, P.; Hubert, Ph.; Crommen, J. Enantioselective determination of oxprenolol in human plasma using dialysis coupled on-line to reversedphase chiral liquid chromatography. J. Pharm. Biomed. Anal. 1997, 15, 1365-1374.

39. Yebra-Biurrun, M.C. Flow injection determination methods of ascorbic acid. Talanta 2000, 52, 367-383.

40. Iwase, H. Routine high-performance liquid chromatographic determination of ascorbic acid in foods using L-methionine for the preanalysis sample stabilization. Talanta $\mathbf{2 0 0 3}$, 60, 1011-1021.

41. Vinci, G.; Botre, F.; Mele, G. Ruggieri, G. Ascorbic acid in exotic fruits: a liquid chromatographic investigation. Food Chem. 1995, 53, 211-214.

42. Jennings, W.G.; Filsoof, M. Comparison of sample preparation techniques for gas chromatographic analysis, J. Agric. Food Chem. 1977, 25, 440-445.

43. Schure, M.R.; Barman, B.N.; Giddings, J.C.; Deconvolution of nonequilibrium band broadening effects for accurate particle size distributions by sedimentation field-flow fractionation, Anal. Chem. 1989, 61, 2735-2734.

44. Zhuravlev, N.D.; Siepmann, J.I. Surface coverages of bounded-phase ligands on silica: A computational study. Anal. Chem. 2001, 73, 4006-4011.

45. Wick, C.D.; Siepmann, J.I.; Schure, M.R. Molecular simulation of concurrent gas-liquid interfacial adsorption and partitioning in gas-liquid chromatography. Anal. Chem. 2002, 74, 3518-3524.

46. Wick, C.D.; Siepmann, J.I.; Schure, M.R. Simulation studies on the effects of mobilephase modification on partitioning in liquid chromatography. Anal. Chem. 2004, 76, 2886-2892.

47. Rafferty, J.L.; Zhang, L.; Siepmann, J.I.; Schure, M.R. Retention mechanism in reversedphase liquid chromatography: A molecular perspective. Anal. Chem. 2007, 79, 6551-6558.

48. LoBrutto, R.; Bereznitski, Y.; Noval, T.J.; DiMichele, L.; Pan, L.; Journet, M.; Kowal, J., Grinberg, N., Kinetic analysis and subambient temperature on-line on-column derivatization of an active aldehyde, J. Chromatogr. A 2003, 995, 67-78.

49. Mangani, F.; Luck, G.; Fradeau, Ch.; Verette, E. On-line column-switching high performance liquid chromatography analysis of cardiovascular drugs in serum with automated sample clean-up and zone cutting technique to perform chiral separation. J. Chromatogr. A 1997, 762, 235-241. 
50. Ma, S.; Shen, S.; Haddad, N.; Tang, W.; Wang, J.; Lee, H.; Yee, N.; Senanayake, C.; Grinberg, N. Chromatographic and spectroscopic studies on the chiral recognition of sulfated b-cyclodextrin as chiral mobile phase additive. Enantiomeric separation of a chiral amine. J. Chromatogr. A 2009, 1216, 1232-1240.

51. Ma, S.; Shen, S.; Lee, H.; Eriksson, M.; Zeng, X.; Xu, J.; Fandrick, K.; Yee, N.; Senanayake, C.; Grinberg, N. Mechanistic studies on the chiral recognition of polysaccharide-based chiral stationary phases using liquid chromatography and vibrational circular dichroism. Reversal of elution order of N-substituted alpha-methyl phenylalanine esters. J. Chromatogr. A 2009, 1216, 3784-3793.

52. Freedman, T.B.; Cao, X.; Dukor, R.K.; Nafie, L.A. Absolute configuration determination of chiral molecules in the solution state using vibrational circular dichroism. Chirality 2003, 15, 743-758.

53. Ma, S.; Shen, S.; Lee, H.; Yee, N.; Senanayake, C.; Nafie, L.A.; Grinberg, N. Vibrational circular dichroism of amylase carbamate: structure and solvent induced conformation changes. Tetrahedron 2008, 19, 2111-2114.

54. Egekeze, J.O.; Danielski, M.C.; Grinberg, N.; Smith, G.B.; Sidler, D.R.; Perpall, H.J.; Bicker, G.R.; Tway, P.C. Kinetic analysis and subambient temperature chromatography of an active ester. Anal. Chem. 1995, 67, 2292-2295.

55. Feibush, B.; Wooley, C.L.; Mani, V. Separation of chiral silicon compounds using permethylated $\alpha-, \beta-$, and $\gamma$-cyclodextrin capillary GC columns. Anal. Chem. 1993, 65, 1130-1133.

56. Jackson, P.T.; Schure, M.R.; Weber, T.P.; Carr, P.W. Intermolecular interactions involved in solute retention on carbon media in reversed-phase high-performance liquid chromatography. Anal. Chem. 1997, 69, 416-425.

57. Rafferty, J.L.; Siepmann, J.I.; Schure, M.R. Molecular-level comparison of alkylsilane and polar embedded reversed-phase liquid chromatography systems. Anal. Chem. 2008, 80, 6214-6221.

58. Moeder, C.; Grinberg, N.; Perpall, H.J.; Bicker, G.; Tway, P. Flow injection determination of Triton-X 100 with on-line solid-phase extraction. Analyst 1992, 117, 767-771.

59. Chong, K; Loughlin, T.; Moeder, C.; Perpall, H.J.; Thompson, R.; Grinberg, N.; Smith, G.B.; Bhupathy, M.; Bicker, G. Drug substance manufacture process control: application of flow injection analysis and HPLC for monitoring an enantiospecific synthesis. J. Pharm. Biomed. Anal. 1996, 15, 111-121.

60. Liu, Y.; Grinberg, N.; Wenslow, R.M.; Thompson, K.C.; Neue, U.D.; Morrison, D.; Walter, T.H.; O'Gara, J.E.; Wyndham, K.D. Evaluation of a $\mathrm{C}_{18}$ hybrid stationary phase using high temperature chromatography. Anal. Chim. Acta 2005, 554, 144-151. 
61. Shen, S.; Lee, H.; Mc Caffrey, J.; Yee, N.; Senanayake, C.; Grinberg, N.; Clark, J. High temperature high performance liquid chromatography of substituted anilines using a $\mathrm{C}_{18}$ Hybrid stationary phases. J. Liq. Chromatogr. \& Rel. Technol. 2006, 29, 2823-2834.

62. Gennaro, M.C.; Bertolo, P.L.; Marengo, E. Determination of aromatic amines at trace levels by ion interaction reagent reversed-phase high performance chromatography. Analysis of hair dyes and other water-soluble dyes. J. Chromatogr. A 1990, 518, 149-156.

63. Nerin, C.; Salafranca, J.; Aznar, M.; Batlle, R. Critical review on recent developments in solventless techniques for extraction of analytes. Anal. Bioanal. Chem. 2009, 393, 809833.

64. Aboul-Enein, H.Y. ed. Separation Techniques in Clinical Chemistry. Marcel Dekker Inc. New York, USA, 2003.

65. Mitra, S. ed. Sample Preparation Techniques in Analytical chemistry. John Wiley \& Sons, Inc. Hoboken, New Jersey, USA. 2003.

66. Angela, M.; Meireles, A. ed. Extracting Bioactive Compounds for Food Products: Theory and Applications. CRC Press Taylor and Francis Group, LLC, USA, 2009.

67. Lunn, G.; Hellwig, L.C. Handbook of Derivatization Reactions for HPLC. Wiley, New York, USA, 2002.

68. Toyo'Oka, T. Modern Derivatization Methods for Separation Science, Wiley, New York, USA, 2002.

69. Hoffmann, G.F.; Sweetman, L. O-(2,3,4,5,6-Pentafluorobenzyl)oxime-trimethylsilyl ester derivatives for sensitive identification and quantitation of aldehydes, ketones, and oxoacids in biological fluids. Clin. Chim. Acta, 1991, 199, 237-242.

70. Le Lacheur, R.M. Identification of carbonyl compounds in environmental samples. Environ. Sci. Technol, 1993, 27, 2745-2753.

71. Luo, X.P.; Yazdanpanah, M.; Bhooi, N.; Lehotay, D.C., Determination of aldehydes and other lipid peroxidation products in biological samples by gas chromatography-mass spectrometry. Anal. Biochem. 1995, 228, 294-298.

72. Yu, J.; Flagan, R.C.; Seinfeld, J.H. Identification of products containing -COOH, -OH, and $-\mathrm{C}=\mathrm{O}$ in atmospheric oxidation of hydrocarbons. Environ. Sci. Technol. 1998, 32, 2357-2370.

73. Theodoridis, G.; de Jong, G.J. Solid-phase microextraction: a new tool in contemporary bioanalysis. Adv. Chromatogr. 2005, 43, 231-271.

74. Matthees, D.P.; Purdy, W.C. Naphthyldiazoalkanes as derivatizing agents for the highperformance liquid chromatographic detection of fatty acids. Anal. Chim. Acta 1979, 109, 61-66.

75. Nagels, L.; Debeuf, C.; Esmans, E. Quantitative determination of quinic acid and derivatives by high-performance liquid chromatography after derivatization with pbromophenacyl bromide. J. Chromatogr. A 1980, 190, 411-417. 
76. Hemming, B.C.; Gubler, C.J. High-pressure liquid chromatography of $\alpha$-keto acid 2,4dinitrophenylhydrazones. Anal. Biochem. 1979, 92, 31-40.

77. Dünges, W. 4-bromomethyl-7-methoxycoumarin as a new fluorescence label for fatty acids. Anal. Chem. 1977, 49, 442-445.

78. Duenges, W.; Seiler, N. High-performance liquid chromatographic separation of esters of 4-hydroxymethyl-7-methoxy-coumarin. A method for the determination of acidic compounds in the picomole range. J. Chromatogr. 1978, 145, 483-488.

79. Valdez, D.; Reier, J. C. Derivatization of glycols, hydroxyamines, and polyols at trace levels with 3,5-dinitrobenzoyl chloride utilizing aqueous to nonaqueous phase transfer on a reverse phase cartridge. J. Liq. Chromatogr. 1987, 10, 863-880.

80. Karlsson, K.E.; Wiesler, D.; Alasandro, M.; Novotny, M. 7-[(Chlorocarbonyl)methoxy]4-methylcoumarin: A novel flourescent reagent for the precolumn derivatization of hydroxy compounds in liquid chromatography. Anal. Chem. 1985, 57, 229-234.

81. Gilbert-Lopez, B; Garcia-Reyes, J. F.; Molina-Diaz, M. Sample treatment and determination of pesticide residues in fatty vegetable matrices: A review. Talanta 2009, 79, 109-128.

82. Gonzalez-Rodriguez, R.M.; Cancho-Grande, B.; Simal-Gandara, J.; Multiresidue determination of 11 new fungicides in grapes and wines by liquid-liquid extraction/cleanup and programmable temperature vaporization injection with analyte protectants/gas chromatography/ion trap mass spectrometry. J. Chromatogr. A 2009, 216, 6033-6042.

83. Clausse, D.; Gomez, F.; Dalmazzone, C.; Noik, C. A method for the characterization of emulsions, thermogranulometry: Application to water-in-crude oil emulsion, J. Colloid Interface Sci. 2005, 287, 694-703.

84. Colgrove, S. G.; Svec, J. H. Liquid-liquid fractionation of complex mixtures of organic components, Anal. Chem. 1981, 53, 1737-1742.

85. Czuczwa, J.; Leuenberger, C.; Tremp, J.; Giger, W.; Ahel, M. Determination of trace levels of phenol and cresols in rain by continuous liquid liquid extraction and high performance liquid chromatography. J. Chromatogr. 1987, 403, 233-241.

86. Wood, N. F. Extraction and clean-up of organochlorine pesticide residues by column chromatography. Analyst 1969, 94, 399-405.

87. D’Avolio, A.; Ibanez, A.; Sciandra, M.; Siccardi, M.; Gonzalez de Requena, D.; Bonora, S.; Di Perri, G. Validation of liquid/liquid extraction method coupled with HPLC-UV for measurement of ribavirin in HCV-positive patients. J. Chromatogr. B 2006, 835, 127-130.

88. Luque de Castro, M.D.; Garcia-Ayuso, L.E. Soxhlet extraction of solid materials: An outdated technique with a promising innovative future. Anal. Chim. Acta 1998, 369, 1-10.

89. Sporring, S.; Bowadt, S.; Svensmark, B.; Bjorklund, E. Comprehensive comparison of classic Soxhlet extraction with Soxtec extraction, ultrasonication extraction, supercritical 
fluid extraction, microwave assisted extraction and accelerated solvent extraction for the determination of polychlorinated biphenyls in soil. J. Chromatogr. A 2005, 1090, 1-9.

90. Luque-Garcia, J.L.; Luque de Castro, M.D. Focused microwave-assisted Soxhlet extraction: Devices and applications. Talanta 2004, 64, 571-577.

91. Luque-Garcia, J.L.; Luque de Castro, M.D. Coupling of pressurized liquid extraction to other steps in environmental analysis. Trends Anal. Chem. 2004, 23,102-108.

92. Araki, R.Y.; Dodo, G.H.; Reimer, S.H.; Knight, M.M. Protocol for the determination of selected neutral and acidic semi-volatile organic contaminants in fish tissue. J. Chromatogr. A 2001, 923, 177-185.

93. Suhaj, M. Spice antioxidants isolation and their antiradical activity: a review. J. Food Comp. Anal. 2006, 19, 531-537.

94. Vinatoru, M. An overview of the ultrasonically assisted extraction of bioactive principles from herbs. Ultrason. Sonochem. 2001, 8, 303-313.

95. Santos, H.M.; Capelo, J.L. Trends in ultrasonic-based equipment for analytical sample treatment. Talanta 2007, 73, 795-802.

96. Priego-Capote, F.; Luque De Castro, M.D. Analytical uses of ultrasound I. Sample preparation. Trends Anal. Chem. 2004, 23, 644-653.

97. Herrera, M.C.; Luque De Castro, M.D. Ultrasound-assisted extraction of phenolic compounds from strawberries prior to liquid chromatographic separation and photodiode array ultraviolet detection. J. Chromatogr. A 2005, 1100, 1-7.

98. Rezic, I.; Horvat, A.J.M.; Babic, S.; Kastelan-Macan, M. Determination of pesticides in honey by ultrasonic solvent extraction and thin-layer chromatography. Ultrason. Sonochem. 2005, 12, 477-481.

99. Kimbaris, A.C.; Siatis, N.G.; Daferera, D.J.; Tarantilis, P.A.; Pappas, C.S.; Polissiou, M.G. Comparison of distillation and ultrasound-assisted extraction methods for the isolation of sensitive aroma compounds from garlic (Allium sativum). Ultrason. Sonochem. 2006, 13, 54-60.

100. Domeno, C.; Blasco, M.; Sanchez, C.; Nerin, C. A fast extraction technique for extracting polycyclic aromatic hydrocarbons (PAHs) from lichens samples used as biomonitors of air pollution: Dynamic sonication versus other methods. Anal. Chim. Acta 2006, 569, 103-112.

101. Gu, X.; Cai, J.; Zhu, X.; Su, Q. Dynamic ultrasound-assisted extraction of polyphenols in tobacco. J. Sep. Sci. 2005, 28, 2477-2481.

102. Carpinteiro, J.; Rodriguez, I.; Cela, R. Simultaneous determination of butyltin and phenyltin species in sediments using ultrasound-assisted leaching. Anal. Bioanal. Chem. 2001, 370, 872-877. 
103. Garcia-Valcarcel, A.I.; Tadeo, J.L. A combination of ultrasonic assisted extraction with LC-MS/MS for the determination of organophosphorus pesticides in sludge. Anal. Chim. Acta 2009, 641, 117-123.

104. Rodriguez-Gonzalo, E.; Carabias-Martinez, R.; Cruz, E.M.; Dominguez-Alvarez, J.; Hernandez-Mendez, J. Ultrasonic solvent extraction and nonaqueous CE for the determination of herbicide residues in potatoes. J. Sep. Sci. 2009, 32, 575-584.

105. Cacho, C.; Turiel, E.; Martin-Esteban, A.; Perez-Conde, C.; Camara, C. Clean-up of triazines in vegetable extracts by molecularly-imprinted solid-phase extraction using a propazine-imprinted polymer. Anal. Bioanal.Chem. 2003, 376, 491-496.

106. Camel, V. Microwave-assisted solvent extraction of environmental samples. Trends Anal. Chem. 2000, 19, 229-248.

107. Camel, V. Recent extraction techniques for solid matrices - Supercritical fluid extraction, pressurized fluid extraction and microwave-assisted extraction: Their potential and pitfalls. Analyst 2001, 126, 1182-1193.

108. Richter, B.E. The extraction of analytes from solid samples using accelerated solvent extraction, LC GC: Liquid Chromatography. Gas Chromatogr. 1999, 17, S22-S28.

109. Barriada-Pereira, M.; Gonzalez-Castro, M.J.; Muniategui-Lorenzo, S.; Lopez-Mahia, P.; Prada-Rodriguez, D.; Fernandez-Fernandez, E. Comparison of pressurized liquid extraction and microwave assisted extraction for the determination of organochlorine pesticides in vegetables. Talanta 2007, 71, 1345-1351.

110. Luque-Garcia, J. L.; Luque de Castro, M. D. Where is microwave-based analytical equipment for solid sample pre-treatment going? Trends Anal. Chem. 2003, 22, 90-98.

111. Eiguren Fernandez, A.; Sosa Ferrera, Z.; Santana Rodriguez, J.J. Microwave-assisted extraction of organochlorine compounds in marine sediments with organized molecular systems. Chromatographia 2001, 53, 375-379.

112. Hermo, M.P.; Barron, D.; Barbosa, J. Determination of residues of quinolones in pig muscle: Comparative study of classical and microwave extraction techniques. Anal. Chim. Acta 2005, 539, 77-82.

113. Pino, V.; Ayala, J.H.; Gonzalez, V.; Afonso, A.M. Focused microwave-assisted micellar extraction combined with solid-phase microextraction-gas chromatography/mass spectrometry to determine chlorophenols in wood samples, Anal. Chim. Acta 2007, 582, 10-18.

114. Carabias-Martinez, R.; Rodriguez-Gonzalo, E.; Revilla-Ruiz, P.; Hernandez-Mendez, J. Pressurized liquid extraction in the analysis of food and biological samples. J. Chromatogr. A 2005, 1089, 1-17.

115. Smith, R.M. Superheated water: The ultimate green solvent for separation science. Anal. Bioanal. Chem. 2006, 385, 419-421. 
116. Zuloaga, O.; Etxebarria, N.; Fernandez, L. A.; Madariaga, J. M. Comparison of accelerated solvent extraction with microwave-assisted extraction and Soxhlet for the extraction of chlorinated biphenyls in soil samples. Trends Anal. Chem. 1998, 17, 642647.

117. Shen, J.; Shao, X. A comparison of accelerated solvent extraction, Soxhlet extraction, and ultrasonic-assisted extraction for analysis of terpenoids and sterols in tobacco. Anal. Bioanal. Chem. 2005, 383, 1003-1008.

118. Gomez-Ariza, J.L.; Bujalance, M.; Giraldez, I.; Velasco, A.; Morales, E. Determination of polychlorinated biphenyls in biota samples using simultaneous pressurized liquid extraction and purification. J. Chromatogr. A 2002, 946, 209-219.

119. Herrera, M.C.; Prados-Rosales, R.C.; Luque-Garcia, J.L.; Luque de Castro, M.D. Staticdynamic pressurized hot-water extraction coupled to on-line filtration-solid phase extraction-high-performance liquid chromatography-post-column derivatizationfluorescence detection for the analysis of N-methylcarbamates in foods. Anal. Chim. Acta. 2002, 463, 189-197.

120. Gonzales Osnaya, G.; Soriano del Castillo, J.M.; Molto Cortes, J.C.; Vinuesa, J.M. Extraction and analysis of ochratoxin $\mathrm{A}$ in bread using pressurised liquid extraction and liquid chromatography. J. Chromatogr. A 2006, 1113, 32-36.

121. Pardo, O.; Yusa, V.; Leon, N.; Pastor, A. Determination of bisphenol diglycidyl ether residues in canned foods by pressurized liquid extraction and liquid chromatographytandem mass spectrometry. J. Chromatogr. A 2006, 1107, 70-78.

122. Morales-Munoz, S.; Luque-Garcia, J. L.; Luque de Castro, M. D. Static extraction with modified pressurized liquid and on-line fluorescence monitoring: Independent matrix approach for the removal of polycyclic aromatic hydrocarbons from environmental solid samples. J. Chromatogr. A 2002, 978, 49-57.

123. Juan, C.; Gonzaalez, L.; Soriano, J. M.; Molto, J.C.; Manes, J. Accelerated solvent extraction of ochratoxin A from rice samples. J. Agric. Food Chem. 2005, 53, 9348-9351.

124. Jansena, B.; Nieropa, K.G.J.; Kotteb, M.C.; de Voogta, P.; Verstratena, J. M. The applicability of accelerated solvent extraction (ASE) to extract lipid biomarkers from soils. Appl. Geochem. 2006, 21, 1006-1015.

125. Bjorklund, E.; Sporring, S.; Wiberg, K.; Haglund, P.; von Hillist, C.V. New strategies for extraction and clean-up of persistent organic pollutants from food and feed samples using selective pressurized liquid extraction. Trends Anal. Chem. 2006, 25, 318-325.

126. Campos-Candel, A.; Llobat-Estelles, M.; Mauri-Aucejo, A. R. Desorption of BTEX from activated charcoal using accelerated solvent extraction: evaluation of occupational exposures. Anal. Bioanal. Chem. 2007, 387, 1517 - 1523.

127. Kania-Korwel, I.; Zhao, H.; Norstrom, K. Li, X.; Hornbuckle, K.C.; Lehmer, H.J. Simultaneous extraction and clean-up of polychlorinated biphenyls and their metabolites 
from small tissue samples using pressurized liquid extraction. J. Chromatogr. A 2008, 1214, 37-46.

128. Smith, R.M. Extractions with superheated water. J. Chromatogr. A 2002, 975, 31-46.

129. Smith, R.M. Superheated water chromatography - A green technology for the future. J. Chromatogr. A 2008, 1184, 441-455.

130. Andersen, M.R.; Swanson, J.T.; Porter, N.L.; Richter, R.M. Supercritical fluid extraction as a sample introduction method for chromatography. J. Chromatogr. Sci. 1989, 27, 371377.

131. Ndiomu, D.P.; Simpson, C.F. Some applications of supercritical fluid extraction, Anal. Chim. Acta 1988, 213, 237-243.

132. Taylor, L.T. Supercritical Fluid Extraction, Wiley, New York, NY, 1996.

133. Reid, R. C.; Prausnitz, J. M.; Poling, B. E. The Properties of Gases and Liquids, $4^{\text {th }}$ ed., McGraw-Hill, New York, 1987.

134. Anklam, E.; Berg, H.; Mathiasson, L.; Sharman, M.; Ulberth, F. Supercritical fluid extraction (SFE) in food analysis: A review. Food Addit. Contam. 1998, 15, 729-750.

135. Sahena, F.; Zaidul, I.S.M.; Jinap, S.; Karim, A.A.; Abbas, K.A.; Norulaini, N.A.N.; Omar, A.K.M. Application of supercritical $\mathrm{CO}_{2}$ in lipid extraction - A review. J. Food Eng. 2009, 95, 240-253.

136. Yamini, Y.; Asghari-Khiavi, M.; Bahramifar, N. Effects of different parameters on supercritical fluid extraction of steroid drugs, from spiked matrices and tablets. Talanta 2002, 58, 1003-1010.

137. Librando, V.; Hutzinger, O.; Tringali, G.; Aresta, M. Supercritical fluid extraction of polycyclic aromatic hydrocarbons from marine sediments and soil samples. Chemosphere 2004, 54, 1189-1197.

138. Hamburger, M.; Baumann, D.; Adler, S. Supercritical carbon dioxide extraction of selected medicinal plants - Effects of high pressure and added ethanol on yield of extracted substances. Phytochem. Anal. 2004, 15, 46-54.

139. Pyo, D.; Lim, C. Supercritical fluid extraction of microcystin LR from cyanobacteria using aqueous acetonitrile modifier. J. Liq. Chromatogr. \& Rel. Technol. 2006, 29, 26912700.

140. Gonalves, C.; Pinto, M.D.R.; Alpendurada, M.F. Benefits of a binary modifier with balanced polarity for an efficient supercritical fluid extraction of PAHs from solid samples, followed by HPLC. J. Liq. Chromatogr. \& Rel. Technol. 2001, 24, 2943-2959.

141. Lehotay, S.J. Supercritical fluid extraction of pesticides in foods. J. Chromatogr. A 1997, 785, 289-312.

142. Kaihara, A.; Yoshii, K.; Tsumura, Y.; Ishimitsu, S.; Tonogai, Y. Multi-residue analysis of 18 pesticides in fresh fruits, vegetables and rice by supercritical fluid extraction and 
liquid chromatography-electrospray ionization mass spectrometry. J. Health Sci. 2002, 48, 173-178.

143. Garcia-Rodriguez, D.; Carro-Diaz, A.M.; Lorenzo-Ferreira, R.A. Supercritical fluid extraction of polyhalogenated pollutants from aquaculture and marine environmental samples: A review. J. Sep. Sci. 2008, 31, 1333-1345.

144. Scalia, S.; Ruberto, G.; Bonina, F. Determination of vitamin A, vitamin E, and their esters in tablet preparations using supercritical fluid extraction and HPLC. J. Pharm. Sci. US 1995, 84, 433-436.

145. Antunes, P.; Gil, O.; Bernardo-Gil, M.G. Supercritical fluid extraction of organochlorines from fish muscle with different sample preparation. J. Supercrit. Fluids 2003, 25, 135-142.

146. Nilsson, T.; Bowadt, S.; Bjorklund, E. Development of a simple selective SFE method for the determination of desorption behaviour of PCBs in two Swedish sediments. Chemosphere 2002, 46, 469-476.

147. Westbom, R.; Josefsson, S.; Mathiasson, L.; Bjorklund, E. Determining PCB desorption behaviour on sediments with SFE and investigating the dependency of selective fractions on sediment characteristics. Int. J. Environ. An. Ch. 2007, 87, 259-274.

148. Ramos, L.; Hernandez, L.M.; Gonzalez, M.J. Study of the distribution of the polychlorinated biphenyls in the milk fat globule by supercritical fluid extraction. Chemosphere 2000, 41, 881-888.

149. Arthur, C. L.; Pawliszyn, J. Solid phase microextraction with thermal desorption using fused silica optical fibers. Anal. Chem. 1990, 62, 2145-2148.

150. Pawliszyn, J. Solid Phase Microextraction: Theory and Practice, Wiley, New York, USA, 1997.

151. Pawliszyn, J. Applications of Solid Phase Microextraction (RSC Chromatography Monographs), Royal Society of Chemistry, Cambridge, 1999.

152. Wercinski, S.A.S. Solid Phase Microextraction: A Practical Guide, Marcel Dekker, New York, USA, 1999.

153. Grote, C.; Pawliszyn, J. Solid-phase microextraction for the analysis of human breath Anal. Chem. 1997, 69, 587-596.

154. Valor, I.; Cortada, C.; Molto, J. C. Direct solid phase microextraction for the determination of BTEX in water and waste water. J. High Resolut. Chromatogr. 1996, 19, 472-474.

155. Moder, M.; Schrader, S.; Winkler, M.; Popp, P. Solid-phase microextraction-gas chromatography-mass spectrometry of biologically active substances in water samples. J. Chromatogr. A 2000, 873, 95-106. 
156. Moder, M.; Schrader, S.; Franck, U.; Popp, P. Determination of phenolic compounds in waste water by solid-phase microextraction. Fresenius' J. Anal. Chem. 1997, 357, 326332.

157. Sng, M. T.; Lee, F. K.; Laks, H. A. Solid-phase microextraction of organophosphorus pesticides from water. J. Chromatogr. A. 1997, 759, 225-230.

158. Potter, D. W.; Pawliszyn, J. Rapid determination of polyaromatic hydrocarbons and polychlorinated biphenyls in water using solid phase microextraction and GC-MS. Environ. Sci. Technol. 1994, 28, 298-305.

159. Valor, I.; Perez, M.; Cortada, C.; Apraiz, D.; Molto, J.; Font, G. SPME of 52 pesticides and polychlorinated biphenyls: efficiencies of the SPME coatings PDMS, polyacrylate, PDMS/DVB, carboxen/PDMS and carbowax/DVB. J. Sep. Sci. 2001, 24, 39-48.

160. Shepard, A.B.; Nichols, S.C.; Braithwaite, A. Moisture induced solid phase degradation of L-ascorbic acid - Part 1. a kinetic study using tristimulus colorimetry and a quantitative HPLC assay. Talanta 1999, 48, 585-593.

161. Shepard, A.B.; Nichols, S.C.; Braithwaite, A. Moisture induced solid phase degradation of L-ascorbic acid part 2, separation and characterization of the major degradation products. Talanta 1999, 48, 595-606.

162. Mangani, F.; Cenciarini, R. Solid phase microextraction using fused silica fibers coated with graphitized carbon black. Chromatographia. 1995, 41, 678-684.

163. Martos, P. A.; Pawliszyn, Calibration of solid phase microextraction for air analyses based on physical chemical properties of the coating. Anal. Chem. 1997, 69, 206-215.

164. Kataoka, H.; Lord, H.L.; Pawliszyn, J. Applications of solid-phase microextraction in food analysis. J. Chromatogr. A. 2000, 880, 35-62.

165. Wardencki, W.; Michulec, M.; Curylo, J. A review of theoretical and practical aspects of solid-phase microextraction in food analysis. Int. J. Food Sci. Technol. 2004, 39, 703717.

166. Aulakh, J.S.; Malik, A.K.; Kaur, V.; Schmitt-Kopplin, P. A review on solid phase micro extraction-high performance liquid chromatography (SPME-HPLC) analysis of pesticides. Crit. Rev. Anal. Chem. 2005, 35, 71-85.

167. Demeestere, K.; Dewulf, J.; DeWitte, B.; Van Langenhove, H. Sample preparation for the analysis of volatile organic compounds in air and water matrices. J. Chromatogr. A. 2007, 1153, 130-144.

168. Setkova, L.; Risticevic, S.; Linton, C.M.; Gangfeng, O.; Bragg, L.M.; Pawliszyn, J. Solid-phase microextraction-gas chromatography-time-of-flight mass spectrometry utilized for the evaluation of the new-generation super elastic fiber assemblies. Anal. Chim. Acta 2007, 581, 221-231. 
169. O'Reilly, J.; Wang, O.; Setkova, L.; Hutchinson, J.P.; Chen, Y.; Lord, H.L.; Linton, C.M.; Pawliszyn, J. Automation of solid-phase microextraction. J. Sep. Sci. 2005, 28, 2010-2022.

170. Risticevic, S.; Niri, V.H.; Vuckovic, D.; Pawliszyn, J. Recent developments in solidphase microextraction, Anal. Bioanal. Chem. 2009, 393, 781-795.

171. Baltussen, E.; Sandra, P.; David, F.; Cramers, C. Stir bar sorptive extraction (SBSE), a novel extraction technique for aqueous samples: Theory and principles. J. Microcol. Sep. 1999, 11, 737-747.

172. Bicchi, C; Cordero, C; Rubiolo, P; Sandra, P. Impact of water/PDMS phase ratio, volume of PDMS, and sampling time on Stir Bar Sorptive Extraction (SBSE) recovery of some pesticides with different KO/W. J. Sep. Sci. 2003, 26, 1650-1656.

173. Bicchi, C.; Iori, C.; Rubiolo, P.; Sandra, P. Headspace sorptive extraction (HSSE), stir bar sorptive extraction (SBSE), and solid phase microextraction (SPME) applied to the analysis of roasted Arabica coffee and coffee brew. J. Agric. Food Chem. 2002, 50, 449459.

174. Kolahgar, B.; Hoffmann, A.; Heiden, A.C. Application of stir bar sorptive extraction to the determination of polycyclic aromatic hydrocarbons in aqueous samples. J. Chromatog. A 2002, 963, 225-230.

175. Blasco, C.; Fernandez, M.; Pico, Y.; Font, G. Comparison of solid-phase microextraction and stir bar sorptive extraction for determining six organophosphorus insecticides in honey by liquid chromatography-mass spectrometry. J. Chromatogr. A 2004, 1030, 77 85.

176. Caven-Quantrill, D.J.; Buglass, A.J. Comparison of micro-scale simultaneous distillation-extraction and stir bar sorptive extraction for the determination of volatile organic constituents of grape juice. J. Chromatogr. A 2006, 1117, 121-131.

177. Zuin, V.G.; Schellin, M.; Montero, L.; Yariwake, J.H.; Augusto, F.; Popp, P. Comparison of stir bar sorptive extraction and membrane-assisted solvent extraction as enrichment techniques for the determination of pesticide and benzo[a]pyrene residues in Brazilian sugarcane juice. J. Chromatogr. A 2006, 1114, 180-187.

178. Demyttenaere, J.C.R.; Sanchez Martinez, J.I.; Verhe, R.; Sandra, P.; deKimpe, N. Analysis of volatiles of malt whisky by solid-phase microextraction and stir bar sorptive extraction. J. Chromatogr. A 2003, 985, 221-232.

179. Blasco, C.; Font, G.; Pico, Y. Comparison of microextraction procedures to determine pesticides in oranges by liquid chromatography-mass spectrometry. J. Chromatogr. A 2002, 970, 201-212.

180. David, F.; Tienpont P.; Sandra, B.; Stir-bar sorptive extraction of trace organic compounds from aqueous matrices, LC-GC Europe 2003, 16, 410-417. 
181. Dieza, J.; Dominguez, C.; Guillen Rafael Veasa, D.A.; Barroso, C.G. Optimization of stir bar sorptive extraction for the analysis of volatile phenols in wines. J. Chromatogr. A 2004, 1025, 263-267.

182. Basheer, C.; Lee, H.K.; Obbard, J.P. Determination of organochlorine pesticides in seawater using liquid-phase hollow fibre membrane microextraction and gas chromatography-mass spectrometry. J. Chromatogr. A 2002, 968, 191-199

183. Rasmussen, K.E.; Pedersen-Bjergaard, S. Developments in hollow fibre-based, liquidphase microextraction. Trends Anal. Chem. 2004, 23,1-10.

184. Lezamiz, J.; Barri, T.; Jonsson, J.A.; Skog, K. A simplified hollow-fibre supported liquid membrane extraction method for quantification of 2-amino-1-methyl-6phenylimidazo[4,5-b]pyridine (PhIP) in urine and plasma samples. Anal. Bioanal Chem. 2008, 390, 689-696.

185. Ettre, L.S. The beginnings of headspace analysis. LC GC North America 2002, 20, 1120 1129.

186. Snow, N. H.; Slack, G. C. Head-space analysis in modern gas chromatography. Trends Anal. Chem. 2002, 21, 608-617.

187. Wood, D.C.; Miller, J.M.; Christ, I. Headspace liquid microextraction. LC-GC Europe 2004, 17, 573-579.

188. Wu, Y.; Xia, L.; Chen, R.; Hu, B. Headspace single drop microextraction combined with HPLC for the determination of trace polycyclic aromatic hydrocarbons in environmental samples Talanta 2008, 74, 470-477.

189. Fiamegos, Y.C.; Stalikas, C.D. Gas chromatographic determination of carbonyl compounds in biological and oil samples by headspace single-drop microextraction with in-drop derivatisation. Anal. Chim. Acta 2008, 609, 175-183.

190. Zhang, T.; Chen, X.; Li, Y.; Liang, P. Application of headspace liquid-phase microextraction to the analysis of volatile halocarbons in water. Chromatographia 2006, 63, 633-637.

191. Lambropoulou, D.A.; Konstantinou, I.K.; Albanis, T.A. Recent developments in headspace microextraction techniques for the analysis of environmental contaminants in different matrices. J. Chromatogr. A 2007, 1152, 70-96.

192. Ducki, S.; Miralles-Garcia, J.; Zumbe, A.; Tornero, A.; Storey, D.M. Evaluation of solidphase micro-extraction coupled to gas chromatography-mass spectrometry for the headspace analysis of volatile compounds in cocoa products. Talanta 2008, 74, 11661174.

193. Chai, M.K.; Tan, G.H. Validation of a headspace solid-phase microextraction procedure with gas chromatography-electron capture detection of pesticide residues in fruits and vegetables. Food Chem. 2009, 117, 561-567. 
194. Saesim, N.; Kanchanamayoon, W. Evaluation of headspace solid-phase microextraction and direct solid-phase microextraction for analysis of trihalomethanes in water samples. Res. J. Appl. Sci. 2009, 4, 80-84.

195. McComb, M.E.; Oleschuk, E.; Giller, R.D.; Gesser, H.D. Microextraction of volatile organic compounds using the inside needle capillary adsorption trap (INCAT) device. Talanta 1997, 44, 2137-2143.

196. Kubinec, R.; Berezkin, V.G.; Gorova, R.; Addova, G.; Mracnova, H.; Sojak, L. Needle concentrator for gas chromatographic determination of BTEX in aqueous samples. J. Chromatogr. B 2004, 800, 295-301.

197. Wang, A.; Fang, F.; Pawliszyn, J. Sampling and determination of volatile organic compounds with needle trap devices. J. Chromatogr. A 2005, 1072, 127-135.

198. Jochmann, M.A.; Kmiecik, M.P.; Schmidt, T.C. Solid-phase dynamic extraction for the enrichment of polar volatile organic compounds from water. J. Chromatogr. A 2006, 1115, 208-216.

199. Bicchi, C.; Cordero, C.; Liberto, E.; Rubiolo, P.; Sgorbini, B. Automated headspace solid-phase dynamic extraction to analyse the volatile fraction of food matrices. J. Chromatogr. A 2004, 1024, 217-226.

200. Hennion, M.C. Solid-phase extraction: Method development, sorbents, and coupling with liquid chromatography. J. Chromatogr. A 1999, 856, 3-54.

201. Salvado, V.; Alcaide, A.; Carandell, N.; Hidalgo, M. Evaluation of extraction procedures of organochlorine pesticides from natural waters and sediments. Int. J. Environ. An. Ch. 2001, 81, 243-256.

202. Ballesteros, E.; Parrado, M.J. Continuous solid-phase extraction and gas chromatographic determination of organophosphorus pesticides in natural and drinking waters. J. Chromatogr. A 2004, 1029, 267-273.

203. Sun, C.; Dong, Y.; Xu, S.; Yao, S.; Dai, J.; Han, S.; Wang, L. Trace analysis of dissolved polychlorinated organic compounds in the water of the Yangtse River (Nanjing, China). Environ. Pollut. 2002, 117, 9-14.

204. Pena, M.T.; Casais, M.C.; Mejuto, M.C.; Cela, R. Development of a matrix solid-phase dispersion method for the determination of polycyclic aromatic hydrocarbons in sewage sludge samples. Anal. Chim. Acta, 2008, 626, 155-165.

205. Michałowicz, J.; Bukowska, B.; Duda, W. The differences in phenolic content in rivers exposed and non-exposed to anthropogenic contamination. Chemosphere 2008, 71, 735741.

206. Yang, S.; Carlson, K.H. Solid-phase extraction-high-performance liquid chromatography-ion trap mass spectrometry for analysis of trace concentrations of macrolide antibiotics in natural and waste water matrices. J. Chromatogr. A 2004, 1038, 141-155. 
207. Watanabe, E.; Baba, K.; Eun, H. Simultaneous determination of neonicotinoid insecticides in agricultural samples by solid-phase extraction cleanup and liquid chromatography equipped with diode-array detection. J. Agr. Food Chem. 2007, 55, 3798-3804.

208. Conka, K.; Drobna, B.; Kocan, A.; Petrik, J. Simple solid-phase extraction method for determination of polychlorinated biphenyls and selected organochlorine pesticides in human serum. J.Chromatogr. A 2005, 1084, 33-38.

209. Forst, C.; Stieglitz, L.; Zwick, G. Isomer-specific determination of PCDD/PCDF in oil extracts from water leachates of a waste landfill. Chemosphere 1988, 17, 1935-1944.

210. Dirtu, A.C.; Roosens, L.; Geens, T.; Gheorghe, A.; Neels, H.; Covaci, A. Simultaneous determination of bisphenol A, triclosan, and tetrabromobisphenol A in human serum using solid-phase extraction and gas chromatography-electron capture negativeionization mass spectrometry. Anal. Bioanal. Chem. 2008, 391, 1175-118.

211. Walton, H. F.; Rocklin R. D. Ion Exchange in Analytical Chemistry, CRC Press, Boca Raton, Fla., 1990.

212. Xue, X.; You, J. He, P. Simultaneous determination of five fat-soluble vitamins in feed by high-performance liquid chromatography following solid-phase extraction. J. Chromatogr. Sci. 2008, 46, 345-350.

213. Wania, F.; Shen, L.; Lei, Y.D.; Teixeira, C.; Muir, D.C.G. Development and calibration of a resin-based passive sampling system for monitoring persistent organic pollutants in the atmosphere. Environ. Sci. Technol. 2003, 37, 1352-1359.

214. Fontanals, N.; Marce, R.M; Borrull, F. New hydrophilic materials for solid-phase extraction. Trends Anal. Chem. 2005, 24, 394-406.

215. Andersson, L.I. Molecular imprinting for drug bioanalysis: A review on the application of imprinted polymers to solid-phase extraction and binding assay. J. Chromatogr. B 2000, 739, 163-173.

216. Andersson, L.I.; Nicholls, I.A. Molecularly imprinted polymers in separation science. J. Chromatogr. B 2004, 804, 1. 